\title{
BEHAVIOR OF RC BEAMS FLEXURALLY STRENGTHENED WITH NSM CFRP LAMINATES
}

\author{
S. J. E. Dias ${ }^{1}$, J. A. O. Barros ${ }^{2}$ and Worajak Janwaen ${ }^{3}$ \\ ${ }^{1}$ Assistant Prof., ISISE, Dep. of Civil Eng., Univ. of Minho, Azurém, 4810-058 Guimarães, Portugal, sdias@civil.uminho.pt \\ 2 Full Prof., ISISE, Dep. of Civil Eng., Univ. of Minho, Azurém, 4810-058 Guimarães, Portugal, barros@civil.uminho.pt \\ ${ }^{3}$ PhD Student, ISISE, Dep. of Civil Eng., Univ. of Minho, Azurém, 4810-058 Guimarães, Portugal, tontrakarn.w@gmail.com
}

\begin{abstract}
An experimental program was carried out to investigate the behavior of RC beams flexurally strengthened using the NSM technique with CFRP laminates. Four beams were tested, a reference beam without CFRP, and three beams flexurally strengthened using different percentage of laminates. The experimental results show that NSM CFRP laminates is an effective solution to increase cracking, yielding and maximum loads of beams failing in bending. Furthermore, the high tensile strength of the CFRP was effectively mobilized. By increasing the CFRP percentage, the load carrying capacity of the NSM beams increased, while the ductility level decreased. Taking into account the experimental results, the predictive performance of the analytical formulation proposed by the ACI was assessed considering two methodologies to determine the maximum strain that can be applied to the CFRP: i) the ACI proposal; ii) the equation proposed by Barros et al. (2007). ACI formulation provides safe results by using both methodologies, but the Barros et al. equation ensures better predictions. A numerical strategy was used to evaluate the load-deflection relationship of the tested beams and to highlight the influence of the longitudinal bars percentage, the CFRP percentage and the concrete strength on the NSM flexural strengthening effectiveness of RC beams.
\end{abstract}

KEYWORDS: NSM CFRP laminates, Flexural strengthening, RC beams, Experimental results, Analytical study, Numerical simulation

\section{INTRODUCTION}

Using advanced composites materials like carbon fiber reinforced polymers (CFRP), competitive structural strengthening solutions can be developed due to the high strength-to-weight ratio, high durability (non-corrodible), electromagnetic neutrality, ease of handling, rapid execution with low labor, and practically unlimited availability in size, geometry and dimension of these materials [1-3].

For the flexural strengthening, CFRP can be applied according to the followings two main techniques: Externally Bonded Reinforcement (EBR) where the CFRP (wet lay-up sheets or laminates) is bonded to the tension face of the 
elements to be strengthened [4-7]; Near Surface Mounted (NSM) where CFRP bars (circular, square or rectangular cross section) are introduced into pre-cut slits opened on the concrete cover of the elements to strengthen [6-16].

Several experimental works [6-8] have demonstrated that the NSM technique provides higher strengthening effectiveness than the EBR technique with CFRP systems. This fact is derived from the better CFRP-concrete bond performance (higher anchoring capacity to the CFRP) that can be mobilized in the NSM technique, by delaying the CFRP debonding (in some cases the CFRP tensile rupture can be achieved), which provides a more efficient use of the reinforcement material (increase of the ratio of FRP strain at failure to its maximum strain). A further advantage of the NSM technique is its ability to significantly reduce the probability of harm resulting from acts of vandalism, mechanical damages and aging effects (the CFRP is protected by the concrete cover). When the NSM is used, the appearance of a structural strengthened element is practically unaffected by the strengthening intervention. NSM requires no surface preparation work and, after cutting the slit, requires minimal installation time compared to the EBR technique.

In terms of the NSM strengthening technique, square or rectangular cross section bars explore better the slits' geometry (vertical and parallel sides) since a more uniform adhesive thickness is achieved. Furthermore, in the case of circular cross section bars it is possible to occur the splitting of the epoxy cover due to the development of stresses perpendicular to the CFRP [12]. The narrow strips of CFRP laminates of rectangular cross section maximize the ratio of the bond surface to the cross-section area, minimizing the bond stresses for the same tensile force in the CFRP. Other advantage of using laminates is related with the simplicity of opening the slits where a single saw cut is normally enough for obtaining the slit, while round/square bars require two saw cuts and the removal of the concrete in between [17].

The available experimental research indicates that NSM technique with CFRP laminates applied in the flexural strengthening of RC beams improves the post-cracking stiffness, the load at the yielding of steel reinforcement and the ultimate load [10-12]. The level of strengthening effectiveness provided by the NSM technique with CFRP laminates is influenced by some parameters like the reinforcement ratio of existing longitudinal steel bars $\left(\rho_{s}\right)$ and CFRP laminates $\left(\rho_{f}\right)$, the relative position of steel and strips, the distance between consecutive strips, and the loading pattern [6-7, 10-11]. Experimental research has shown the possibility of increasing the maximum load from $35 \%\left(\rho_{f}=0.21 \%, \rho_{s}=0.57 \%\right.$, [6]) to $221 \%\left(\rho_{f}=0.2 \%, \rho_{s}=0.27 \%,[11]\right)$. Barros et al. [6] also demonstrated that exists a clear tendency for the decrease of the maximum strain in the NSM CFRP laminates that can be mobilized in flexurally strengthened RC beams with the increase of the equivalent reinforcement ratio $\rho_{s l, e q}$ (steel and CFRP converted into equivalent steel).

In this study, the effectiveness of the NSM technique with CFRP laminates for the flexural strengthening of RC beams is assessed by evaluating the effect of the CFRP percentage (it was adopted the same amount of existing steel reinforcement for all of the tested beams) in the structural behavior of rectangular cross section RC beams. The experimental program which was carried out is described in detail (beam prototypes, materials properties, application of 
the NSM CFRP laminates, test set-up and monitoring system), and the obtained results are presented and analyzed in terms of the structural behavior of the RC beams, failure modes and performance of the NSM technique with CFRP laminates. Considering the results obtained in the tested NSM beams, the predictive performance of the analytical formulation proposed by ACI was assessed. For this purpose, two methodologies for determining the maximum strain that can be applied to the laminates ( $\varepsilon_{f d}$ - debonding strain of the NSM CFRP laminates) were analysed (the proposal of the ACI [1] and the equation proposed by Barros et al. [6]). To simulate the response of the tested RC beams in terms of force versus deflection, a numerical strategy based on a cross section layer model and matrix stiffness method was used. The numerical strategy is described and its predictive performance is assessed in this work. Finally, a parametric study was executed to highlight the influence of the percentage of longitudinal bars, the percentage of CFRP and the concrete strength on the NSM flexural strengthening effectiveness of RC beams.

\section{EXPERIMENTAL PROGRAM}

\subsection{Beam prototypes}

The experimental program was composed of four RC beams with a rectangular cross section of $150 \times 300 \mathrm{~mm}^{2}$, a total length of $2600 \mathrm{~mm}$ and a span length of $2400 \mathrm{~mm}$. The longitudinal steel reinforcement consisted of $2 \mathrm{bars}$ of $8 \mathrm{~mm}$ diameter $(2 \phi 8)$ in the compression zone and 2 bars of $10 \mathrm{~mm}$ diameter $(2 \phi 10)$ in the tension surface. Steel stirrups of $6 \mathrm{~mm}$ diameter spaced at $75 \mathrm{~mm}(\phi 6 @ 75 \mathrm{~mm})$ were adopted for transversal steel reinforcement in order to ensure flexural failure mode for all the tested beams. Fig. 1 represents the geometry, the reinforcement arrangements, the loading configuration and the support conditions for the type of beams of the experimental program. The concrete clear cover of the longitudinal tensile bars was $20 \mathrm{~mm}$.

The general information of the four tested RC beams is represented in Table 1. All the tested beams had a percentage of longitudinal tensile steel bars $\left(\rho_{s l}\right)$ of about $0.38 \%$. The reference beam without CFRP was designated as "REF", and the S1L, S2L and S3L beams were those flexurally strengthened using different CFRP percentages $\left(\rho_{f}\right): 0.03 \%(\mathrm{~S} 1 \mathrm{~L}$ beam strengthened with 1 NSM CFRP laminate), 0.06\% (S2L beam strengthened with 2 NSM CFRP laminates) and 0.09\% (S3L beam strengthened with 3 NSM CFRP laminates). Fig. 2 represents details about the adopted NSM CFRP configurations for the strengthened RC beams. The CFRP laminates used in the present experimental program had a cross section of 1.4 (thickness) $\times 10$ (depth) $\mathrm{mm}^{2}$ and a length of $2300 \mathrm{~mm}$ according to Fig. 2 (the distance between the extremities of the laminates and the supports was $50 \mathrm{~mm}$ ). 


\subsection{Materials properties}

The concrete compressive strength was evaluated when the beam tests were realized. In order to do it, direct compression tests were carried out with cylinders of $150 \mathrm{~mm}$ diameter and $300 \mathrm{~mm}$ hight, according to EN 206-1 [18]. The values of the main tensile properties of the high bond steel bars $(6,8$ and $10 \mathrm{~mm}$ diameter $)$ used in the tested beams were obtained from uniaxial tensile tests performed according to the recommendations of EN 10002 [19]. CFK 150/2000 S\&P laminates were used in the present experimental research and the tensile properties were evaluated following the recommendations of ISO 527-5 [20]. Table 2 includes the average values obtained from these experimental tests.

S\&P Resin 220 epoxy adhesive was used to bond the CFRP laminates to the concrete substrate. The instantaneous and long term tensile behavior of this adhesive was investigated by Costa and Barros [21]. At 3 days, at which the elasticity modulus $\left(\boldsymbol{E}_{\mathbf{0 . 5} \sim 2.5 \%}\right)$ attained a stabilized value, the tensile strength and the $\boldsymbol{E}_{0.5 \sim 2.5 \%}$ were determined in accordance with the ISO 527-2 recommendations [22], and the obtained results were $20 \mathrm{MPa}$ and $7 \mathrm{GPa}$, respectively.

\subsection{Application of the NSM CFRP laminates}

To apply the CFRP laminates using NSM technique, the following procedures were executed. First, a diamond cutter was used to open on the concrete cover of the tension face slits of about $5 \mathrm{~mm}$ wide and $15 \mathrm{~mm}$ deep in accordance with the pre-defined arrangement for the laminates (Fig. 2). Then, the slits were cleaned by compressed air and the laminates (supplied in rolls of $150 \mathrm{~m}$, with a cross-section of $1.4 \times 10 \mathrm{~mm}^{2}$ ) were cut with a length of $2300 \mathrm{~mm}$ and then cleaned with acetone. The epoxy adhesive was produced according to the supplier recommendations and then the slits were filled with the adhesive. An adhesive layer was applied on the faces of the laminates and the laminates were inserted into the slits. Finally, the adhesive in excess was removed.

\subsection{Test setup and monitoring system}

The four point beam bending tests (Fig. 3) were executed under displacement control at a deflection rate of $0.02 \mathrm{~mm} / \mathrm{second}$. All beams were instrumented to measure the applied load, deflections and strains in the CFRP laminates and longitudinal tensile steel reinforcement. The deflection of the tested beams was measured by five displacement transducers (LVDT 1 to LVDT 5) as shown in Fig. 4a. To evaluate the strains on the steel bars, three strain gauges were installed in the two bottom longitudinal steel bars (SGS1 to SGS3) according to the configuration represented in Fig. $4 \mathrm{~b}$. In the NSM strengthened beams, five strain gauges were installed in one CFRP laminate (SGL1 to SGL5) as represented in Fig. 4c. 


\section{EXPERIMENTAL RESULTS AND DISCUSSION}

\subsection{Load carrying capacity of the tested beams}

Fig. 5 shows the relationship between the applied force and the deflection at mid-span, $F-u$, for the tested RC beams. This figure shows that the experimental load-displacement curves of the beams had three important phases, until cracking of the concrete, between concrete cracking and yield initiation of the longitudinal steel reinforcement, and between steel reinforcement yield initiation and ultimate load. In the first stage, before concrete cracking, all the tested beams developed linear elastic behavior, where the NSM laminates had only a slight effect on the cracking load. In the second stage, from concrete cracking up to yield initiation of the steel reinforcement, the NSM laminates increased the beam's stiffness and the yielding load. The almost linear slope of the second phase indicates that the linear nature of the behavior of both steel bars (up to yield initiation) and CFRP laminates determined this cracking propagation phase. In the third phase, comprised the time between the steel yielding initiation and the failure of the beam, the unstrengthened reference beam, as expected, behaved in a plastic manner. The almost linear behavior of the third phase of strengthened beams is due to the contribution of the CFRP, since the laminates have linear elastic behavior, while steel reinforcement was in a plastic stage and cracked concrete is too damaged. The stiffness of this phase in the strengthened beams increased almost proportionally with the CFRP percentage $\left(\rho_{f}\right)$, with a significant increase in the beam's load carrying capacity.

Table 3 shows the summary of the results of the tested RC beams in terms of cracking $\left(F_{c r a c k}\right)$, yielding $\left(F_{s y}\right)$ and maximum $\left(F_{\max }\right)$ load (see also Fig. 5). The values of the deflection at mid-span for the load $F_{s y}\left(u_{F s y}\right)$ and for the load $F_{\max }\left(u_{F \max }\right)$ are also indicated in Table 3 . The yielding load is herein defined as the load at which a significant decrease of stiffness has occurred, corresponding to the transition between the $2^{\text {nd }}$ and the $3^{\text {rd }}$ phases of the beam's behavior.

Based on Table 3, the values of cracking load $\left(F_{\text {crack }}\right)$ of REF, S1L, S2L and S3L beams, were respectively, $20.1 \mathrm{kN}$, $21.0 \mathrm{kN}, 22.2 \mathrm{kN}$ and $24.0 \mathrm{kN}$, which evidences an increase of the $F_{\text {crack }}$ with $\rho_{f}$. The yielding load, $F_{\text {sy }}$, increased almost linearly with $\rho_{f}(10 \%, 23 \%$ and $34 \%$ for the beams S1L, S2L and S3L, respectively), as shown in Fig. 6a. This occurs because of the increase of the flexural stiffness with $\rho_{f}$ in the $2^{\text {nd }}$ phase of the beam's behavior. The use of NSM CFRP laminates increased significantly the ultimate load carrying capacity of RC beams. In fact, an increase of $42 \%, 80 \%$ and $103 \%$ was obtained in terms of maximum load $\left(F_{\max }^{S t r}\right)$ in the S1L, S2L and S3L, respectively, when compared to the maximum load of the reference beam $\left(F_{\max }^{R e f}\right)$. The maximum load $F_{\max }^{S t r}$ with $\rho_{f}$ did not increase as much as the one registered for the $F_{s y}$ (Fig. 6a), due to the different types of failure modes that occurred when increasing $\rho_{f}$.

For the strengthened beams, the deflection at maximum load $(41.2 \mathrm{~mm}, 43.6 \mathrm{~mm}$ and $38.9 \mathrm{~mm}$, respectively, for beams S1L, S2L and S3L) was more than four times the deflection at yield initiation $(8.5 \mathrm{~mm}, 9.4 \mathrm{~mm}$ and $9.7 \mathrm{~mm}$, respectively, 
for beams S1L, S2L and S3L), with a significant plastic incursion in the steel reinforcement, which assures the required level of deflection ductility for this type of RC structures. The parameter $\left(u_{F \operatorname{Str}}^{S t r} / u_{F s y}^{S t r}\right) /\left(u_{F \max }^{R e f} / u_{F s y}^{R e f}\right)$, herein designated by ductility index, was evaluated in order to define the effect of the percentage of the CFRP $\left(\rho_{f}\right)$ in the ductility level of the NSM strengthened beams $\left(u_{F m a x}^{S t r}\right.$ and $u_{F s y}^{S t r}$ are, respectively, the values of $u_{F m a x}$ and $u_{F s y}$ for NSM strengthened beams; $u_{F \operatorname{Rmax}}^{R e f}$ and $u_{F s y}^{R e f}$ are, respectively, the values of $u_{F \max }$ and $u_{F s y}$ for the reference beam). Considering the results

of Table 3, the values of the parameter $\left(u_{F \operatorname{Str}}^{S t} / u_{F s y}^{S t r}\right) /\left(u_{F \operatorname{Rmax}}^{\operatorname{Ref}} / u_{F s y}^{\operatorname{Ref}}\right)$ for the beams S1L $\left(\rho_{f}=0.03 \%\right), \mathrm{S} 2 \mathrm{~L}\left(\rho_{f}=0.06 \%\right)$ and S3L $\left(\rho_{f}=0.09 \%\right)$ were, respectively, $0.89,0.85$ and 0.74 . According to Fig. $6 \mathrm{~b}$ it is possible to verify a decrease of the ductility index of the NSM strengthened beams with the increase of the percentage of CFRP.

\subsection{Crack pattern and failure modes}

Fig. 7 shows the final crack pattern of the tested RC beams. The first cracks occurred in the pure bending zone (between the load sections). By increasing the load even more, the cracks became wider and new cracks started to appear in the shear span of the beams. The crack pattern on the reference beam basically consisted of flexural cracks, while in the NSM beams also occurred flexural-shear cracks. By strengthening RC beams with NSM CFRP laminates, the average distance between cracks decreased. In fact, the values of the average distance between cracks in beams REF, S1L, S2L and S3L were, respectively, $98.2 \mathrm{~mm}, 76.2 \mathrm{~mm}, 75.8 \mathrm{~mm}$ and $67 \mathrm{~mm}$. The analysis of the cracking process of the tested beams up to their failure has shown that the cracks' widths have decreased by strengthening the RC beams with NSM CFRP laminates. From the comparison of the final crack pattern of the NSM beams, it is possible to conclude that the length of the beams's cracked band has increased with the increase of the percentage of CFRP. In fact, the values of the beams's cracked band were $1530 \mathrm{~mm}, 1685 \mathrm{~mm}, 1810 \mathrm{~mm}$, and $1865 \mathrm{~mm}$ for the beams, respectively, REF, S1L, S2L and S3L.

Three types of failure modes occurred in the tested RC beams: i) the reference beam failed by the concrete crushing after the yielding of the tensile steel reinforcements (see Fig. 8a); ii) the strengthened beam with one laminate (beam S1L) failed by the rupture of the CFRP (see Fig. 8b) after the yielding of the tensile steel reinforcements; iii) the strengthened beams with two laminates (beam S2L) and three laminates (beam S3L) failed by the detachment of the CFRP (intermediate crack debonding) after the yielding of the tensile steel reinforcements. In fact, in these last two beams as soon as the critical flexural crack reaches the CFRP (near the loaded section), it propagated horizontally along the CFRP NSM system towards the closest extremity, causing the failure of the strengthening system. Details about the development of the failure mode of the S2L and S3L beams are shown in Fig. 8c and Fig. 8d, respectively. 


\subsection{Strains in CFRP laminates and tensile steel reinforcements}

Fig. 9 shows the relationship between the applied load and the strains in the SG's positioned in the longitudinal steel bars and in the monitored CFRP laminates. It was only possible to obtain the evolution of the strains in the longitudinal steel bars until load levels lower than the maximum load. However, the obtained evolution of strains indicates that the longitudinal steel bars had already developed a significant plastic deformation when strain measuring has ended. As shown in Fig. 9, the CFRP strain ( $\left.\varepsilon_{C F R P}\right)$ evolution during the loading process presented the following four stages: 1) a linear, but very small increase with the load up to the concrete crack initiation; 2) the highest increment of strain just after the concrete crack initiation, whose amplitude has decreased with $\rho_{f}$, while the force-strain gradient $\left(F-\varepsilon_{C F R P}\right)$ has increased with $\rho_{f}$. Since the cracking load was not too different for the strengthened beams, the almost same energy accumulated by the concrete surrounding the CFRP laminates is transferred to the laminates at concrete crack initiation, inducing an amplitude of strain that is greater the lower the value $\rho_{f}$. After this transitional phase, the gradient of the beam's load versus CFRP strains attains an almost constant value up to the yield initiation of the longitudinal steel bars; 4) this load level corresponds to the initiation of the last stage with a significant decrease of the $F-\varepsilon_{C F R P}$, due to the incapacity of steel bars to support any extra load applied to the beam.

Table 4 includes the strains measured in the monitored laminates up to the maximum load of the NSM strengthened beams, $\varepsilon_{C F R P}^{S G L i}(\mathrm{i}=1$ to 5 , see Fig. 4). It can be observed in Table 4 and Fig. 9 that the maximum strain value was recorded in SGL1 or SGL2, both positioned in the pure bending zone (between the load sections) and SGL5 recorded the lowest strain values in all of the tested beams.

The maximum values of strain recorded in the monitored CFRP laminates up to the maximum load of the NSM strengthened beams $\left(\varepsilon_{C F R P}^{\max }\right)$ are indicated in Table 4. The maximum strains in the CFRP laminates ranged from 14.9\%o (S3L beam) to 17.9\%o (S1L beam). The average value of the maximum strain for the three tested beams was $16.7 \%$ which corresponds to $93 \%$ of its ultimate strain, indicating that this strengthening technique can mobilize stress levels in the CFRP reinforcing elements close to the tensile strength of this composite material (high effectiveness of the NSM technique for the flexural strengthening of RC beams). As a result of the failure modes, the maximum strain in the tested NSM beams was observed in S1L beam (rupture of the CFRP). The detachment of the CFRP in the S2L beam occurred when the CFRP was almost attaining its tensile rupture $\left(\varepsilon_{C F R P}^{\max }=17.4 \%\right.$ that corresponds to $97 \%$ of the ultimate strain of the CFRP) and in this way more delayed than the detachment of the CFRP in the S3L beam, where $\varepsilon_{C F R P}^{\max }=14.9 \%$ (this 
value corresponds to $83 \%$ of the ultimate strain of the CFRP). Based on the results of Table 4 , with increasing the percentage of the CFRP, the strain in the CFRP laminates decreases showing that by increasing the percentage of the CFRP, the probability of using more capacity of CFRP laminates decreases.

Fig. 10 illustrates the variation of strains along half of the CFRP length for various load levels (30\%, 50\%, 70\%, 90\% and $100 \%$ of the maximum load $F_{\max }$ ), where is possible to see that the higher evolution of strains in the CFRP occurs between the SGL1 and SGL4. As expected, for all of the NSM beams, the maximum strain values of the CFRP was observed in the strain gauges SGL1 and SGL2 (almost equal values due to the pure bending moment between the loading sections). In the SGL2 of the S1L beam it is possible to verify that, at the end of the test $(\mathrm{F}=88.4 \mathrm{kN})$ the maximum strain of CFRP was $17.9 \%$, and $67 \%$ of this strain has occurred after the yielding initiation of the steel reinforcement (F $=62.4 \mathrm{kN}$ ), due to a higher stress transfer for the CFRP laminate. In the case of the S2L and S3L beams the above mentioned percentage was $74 \%$ and $71 \%$, respectively.

By taking the variation of the strain for the above mentioned load levels $(30 \%, 50 \%, 70 \%, 90 \%$ and $100 \%$ of the maximum load $\left.F_{\max }\right)$, the corresponding average shear stresses $\left(\tau_{\text {med }}\right)$ were determined using the following equation:

$$
\tau_{\text {med }}=\frac{\Delta F}{2 \times\left(b_{f}+t_{f}\right) \times \Delta L} \quad(\mathrm{kPa})
$$

where $\Delta F$ is the variation of the CFRP axial force that was obtained from:

$$
\Delta F=E_{f} \times \Delta \varepsilon \times t_{f} \times b_{f} \times 10^{-6}(\mathrm{kN})
$$

where $t_{f}, b_{f}$ and $E_{f}$ are, respectively, the thickness, the width and the elasticity modulus of the CFRP laminate, and $\Delta \varepsilon$ is the strain variation between two consecutive strain gauges at a distance $\Delta L$ (in meters). In (2) the units of $E_{f}$, $\Delta \varepsilon, t_{f}, b_{f}$ are, respectively, kiloPascal, microstrains and meters.

From the diagrams of $\tau_{\text {med }}$ represented in Fig. 10, it can be concluded that the shear stress between CFRP and concrete increases with load, from the center to the end of the composite for the beams S2L and S3L (beams where the failure mode was the detachment of the CFRP - see Fig. 8c and 8d). This last tendency did not occur in S1L beam due the failure mode of this beam (CFRP rupture near the loaded section).

\section{APPRAISAL OF THE ACI ANALYTICAL FORMULATION}

Taking into account the results obtained in the tested RC beams flexurally strengthened with NSM CFRP laminates, the performance of the analytical formulation proposed by ACI [1], for the evaluation of the moment capacity of the strengthened flexural RC members with FRP, was appraised. The load carrying capacity of a RC beam flexurally 
strengthened with NSM CFRP laminates failed in bending can be estimated from the design resisting bending moment of its representative cross section, herein designated by $M_{R d}$. According to the ACI analytical formulation, the value of $M_{R d}$ can be found from:

$$
M_{R d}=\phi\left(A_{s l} f_{s y}\left(d_{s}-\beta_{1} x / 2\right)+\gamma_{f} A_{f} f_{f e}\left(d_{f}-\beta_{1} x / 2\right)\right)
$$

where $A_{f}$ is the CFRP cross sectional area, $A_{s l}$ and $f_{s y}$ are the cross sectional area and the yield stress of the longitudinal tensile steel bars, $x$ is the position of the neutral axis, $f_{f e}$ is the effective tensile stress at ultimate conditions in the FRP ( $f_{f e}=E_{f} \varepsilon_{f e}$, where $E_{f}$ is the elasticity modulus of the CFRP and $\varepsilon_{f e}$ is the effective strain level in the CFRP reinforcement at the ultimate limit state), $\phi$ is a strength reduction factor to attend the ductility level of the cross section [1], and $\gamma_{f}=0.85$ is an additional safety factor for the flexural-strengthening contribution of the FRP reinforcement. The parameters $d_{s}$ and $d_{f}$ are the effective depth of the longitudinal steel bars and FRP systems, respectively. The term $\beta_{1}$ is the ratio of the depth of the equivalent rectangular stress block to the depth of the neutral axis [1].

The effective strain $\varepsilon_{f e}$ can be found from:

$$
\varepsilon_{f e}=\varepsilon_{c u} \times\left(\frac{d_{f}-x}{x}\right)-\varepsilon_{b i} \leq \varepsilon_{f d}
$$

where $\varepsilon_{c u}$ is the maximum usable compressive strain in the concrete $(=0.003), \varepsilon_{b i}$ is the strain level in concrete substrate at time of FRP installation and $\varepsilon_{f d}$ is the maximum strain that can be applied to the laminates (debonding strain of the NSM CFRP laminates).

According to ACI [1], for NSM FRP applications, the value of $\varepsilon_{f d}$ may vary from $0.6 \varepsilon_{f u}$ to $0.9 \varepsilon_{f u}$ depending on many factors such as member dimensions, steel and FRP reinforcement ratios, and surface roughness of the FRP. Based on existing studies the recommendation of $\mathrm{ACI}[1]$ for the strain $\varepsilon_{f d}$ is:

$$
\varepsilon_{f d}=0.7 \times \varepsilon_{f u}
$$

Considering available experimental results of RC beams and RC slabs strengthened with NSM CFRP technique, Barros et al. [6] demonstrated that there is a clear tendency for the decrease of the parameter $\varepsilon_{f d} / \varepsilon_{f u}$ with the increase of the equivalent reinforcement ratio $\rho_{s l, e q}$, which was simulated by the following equation:

$$
\varepsilon_{f d}=\left(-32.648 \times \rho_{s l, e q}+0.9606\right) \times \varepsilon_{f u}
$$


where $\rho_{s l, e q}$ is defined by the following equation:

$$
\rho_{s l, e q}=A_{s l} /\left(b \times d_{s}\right)+\left(A_{f} \times E_{f} / E_{s}\right) /\left(b \times d_{f}\right)
$$

where $b$ is the width of the beam's cross section and $E_{s}$ is the elasticity modulus of the longitudinal steel bars.

The analytical values of the maximum load $\left(F_{\max }^{a n a}\right)$ of the tested NSM strengthened beams, estimated considering the ACI formulation (using the average values for the material properties and considering all safety factors as unitary values) when $\varepsilon_{f d}$ is obtained using equations (5) and (6), are compared to the experimental ones ( $\left.F_{\max }^{\exp }\right)$ in Table 5.

A safe prediction means that the ratio between the experimental and the analytical value of $F_{\max }$ is higher than 1.0 $\left(F_{\max }^{\exp } / F_{\max }^{\text {ana }} \geq 1.0\right)$. From the analysis of the values included in Table 5 it can be concluded that ACI formulation provide safe results (Fig. 11) for all of the tested NSM strengthened beams. When the equations (5) and (6) were used to obtain

the value of $\varepsilon_{f d}$, the average value of the $F_{\max }^{\exp } / F_{\max }^{a n a}$ was 1.23 and 1.15 , respectively, which means that equation (6) ensures better predictions. For this better performance of equation (6), it contributed the fact that this equation considers parameters that are related to the performance of RC beams flexurally strengthened with NSM technique using CFRP laminates, whose evaluation was based on the obtained experimental results, namely the equivalent reinforcement ratio $\rho_{s l, e q}$, that includes the percentage of existing steel reinforcement and the percentage of the CFRP.

\section{NUMERICAL SIMULATION AND PARAMETRIC STUDY}

\subsection{Numerical simulation}

Previous work [10] shows that, using a cross section layered model that takes into account the constitutive laws of the intervening materials, and the kinematic and the equilibrium conditions, the deformational behavior of structural elements failing in bending can be predicted from the moment-curvature relation, $\mathrm{M}-\chi$, of the representative cross sections of these elements, using the algorithm described elsewhere [23, 24].

To simulate the behavior of concrete in compression, the stress-strain relationship recommended by model code CEBFIP Model Code 90 [25] was used (see Fig. 12a). Concrete was assumed as behaving linearly up to its tensile strength, while in the post-cracking stage the tension-stiffening diagram, represented in Fig. 12b and investigated by Barros and Fortes [10], was used. In this figure, $f_{c t m}$ is average concrete tensile strength determined from the average compressive strength, $f_{c m}$, by adopting the Eurocode 2 [26] recommendations. The values considered for the parameters $\alpha_{1}$ and $\zeta_{1}$ were, respectively, 0.2 and 4 .

The stress-strain diagram used to model the tension and the compression behavior of steel bars is represented in Fig. 13a [10]. The data defining this relationship is indicated in Table 6. For modeling the tensile behavior of the CFRP 
laminates, the bi-linear elastic stress-strain relationship represented in Fig. 13b was adopted, and using the values indicated in Table 2. The decrease of stiffness simulated by this diagram above a stress level defined by the $\alpha$ parameter aims to indirectly take into account the sliding that occurs between CFRP laminates and surrounding concrete. Experimental and advanced numerical simulations [27] have indicated that this sliding is only significant after yield initiation of the flexural reinforcement, and a value of 0.85 was determined for the $\alpha$ parameter (Fig. 13b).

Fig. 14 compares the relationship between the applied load and the deflection at mid-span recorded experimentally and obtained in the numerical simulations. As Fig. 14 shows, the adopted numerical strategy fits with good accuracy the registered experimental load vs. mid-span deflection curves of the tested beams.

\subsection{Parametric study}

In this section a parametric study is carried out in order to estimate the influence of the following parameters on the NSM flexural strengthening effectiveness: concrete quality by using its compressive strength class, $f_{c k}$; the percentage of existing flexural reinforcement, $\rho_{s l}$; and the percentage of CFRP, $\rho_{f}$. For this purpose the models adopted in the previous section for determining the cross section moment-curvature and the force-deflection relationships were adopted, by changing conveniently the concrete properties according to the recommendations of CEB-FIP Model Code 90 [25] when analyzing the influence of concrete strength class. For each of the above mentioned parameters it was tested three values (25 MPa, $50 \mathrm{MPa}$ and $75 \mathrm{MPa}$ for $f_{c k} ; 0.38 \%, 0.76 \%$ and $1.14 \%$ for $\rho_{s l} ; 0.03 \%, 0.06 \%$ and $0.09 \%$ for $\rho_{f}$ ).

Figs. 15, 16 and 17 present the influence of the aforementioned parameters on the increase in terms of load carrying capacity at serviceability limit state (SLS) conditions $\left(\Delta F_{S L S}=\left(F_{S L S}^{S t r}-F_{S L S}^{R e f}\right) / F_{S L S}^{R e f}\right.$, where $F_{S L S}^{S t r}$ and $F_{S L S}^{R e f}$ are the load carrying capacity at SLS conditions of the strengthened and reference beam, respectively), at yield initiation $\left(\Delta F_{s y}=\left(F_{s y}^{S t r}-F_{s y}^{R e f}\right) / F_{s y}^{R e f}\right.$, where $F_{s y}^{S t r}$ and $F_{s y}^{R e f}$ are the load carrying capacity at yield initiation of the existing flexural steel reinforcement of the strengthened and reference beam, respectively), and at maximum load $\left(\Delta F_{\text {max }}=\left(F_{\max }^{S t r}-F_{\text {max }}^{R e f}\right) / F_{\text {max }}^{R e f}\right.$, where $F_{\text {max }}^{S t r}$ and $F_{\text {max }}^{\text {Ref }}$ are the maximum load of the strengthened and reference beam, respectively). According to the Eurocode 2 [26] the load at SLS conditions is evaluated at a deflection of $L / 250$, where $L$ is the beam's span length.

The obtained results show that the three adopted indicators, $\Delta F_{S L S}, \Delta F_{s y}$ and $\Delta F_{\max }$ decrease with the increase of $\rho_{s l}$, regardless the $\rho_{f}$. The increase level for $\Delta F_{S L S}$ and $\Delta F_{s y}$ was very similar due to the circumstance of the deflection at SLS ( $\left.u_{S L S}\right)$ has been close to the deflection at yield initiation of the flexural reinforcement $\left(u_{s y}\right)$. For beams with $u_{S L S}$ 
much lower than $u_{s y}$, the $\Delta F_{s y} / \Delta F_{S L S}$ should be higher than the values registered in this parametric study. The maximum strengthening effectiveness was registered in terms of $\Delta F_{\text {max }}$. The obtained results demonstrate the relatively small influence of the concrete strength class on the strengthening performance indicator at ultimate limit state conditions $\left(\Delta F_{\max }\right)$, which supports the no consideration of $f_{c k}$ as part of the equation (6). The exceptions occurred in beams of low concrete strength classes combined with relatively high percentage of existing flexural reinforcement. Eq. (6) assumes, however, a linear relation between $\varepsilon_{f d} / \varepsilon_{f u}$ and $\rho_{s l, e q}$, while the parametric study indicates a nonlinear format for the relation between these two entities, which requires further research for obtaining a more precise equation, involving more sophisticated numerical models, capable of capturing all possible failure modes with reliable predictive performance.

\section{CONCLUSIONS}

By carrying out an experimental program, the effectiveness of the NSM technique with CFRP laminates for the flexural strengthening of RC beams was assessed. Furthermore, the influence of the percentage of CFRP laminates in the behavior of RC beams flexurally strengthened with NSM technique was investigated. From the obtained experimental results it can be concluded that:

- Regardless of the percentage of the CFRP laminates adopted in this experimental program, the NSM technique with CFRP laminates was highly effective for the flexural strengthening of RC beams. In fact, the adopted CFRP flexural strengthening configuration has provided an increase in terms of maximum load that ranged between $42 \%$ and $103 \%$ of the maximum load of the reference RC beam. Using three NSM CFRP laminates $\left(\rho_{f}=0.09 \%\right)$ the maximum load of the reference beam was doubled.

- For the range of CFRP percentage values $\left(\rho_{f}\right)$ considered in this work, the strengthening efficacy in terms of yielding load and maximum load has almost increased linearly with the increase of $\rho_{f}$. For beams strengthened with one $\left(\rho_{f}=0.03 \%\right)$, two $\left(\rho_{f}=0.06 \%\right)$, and three $\left(\rho_{f}=0.09 \%\right)$ NSM CFRP laminates, the increase in terms of yielding load was, respectively, $10 \%, 23 \%$ and $34 \%$ of the yielding load of the reference beam, while in terms of maximum load the increase was, respectively, $42 \%, 80 \%$ and $103 \%$.

- In the strengthened beams the deflection at maximum load was more than four times the deflection at yield initiation, with significant plastic incursion in the steel reinforcement, which assures the required level of deflection ductility for this type of RC structure. However, it was verified a decrease of the ductility level of the NSM strengthened beams with the increase of the CFRP percentage. 
- The maximum strains in the CFRP laminates ranged from $14.9 \%$ (S3L beam) to $17.9 \%$ o (S1L beam). The average value of the maximum strain for the three tested beams was $16.7 \%$ which corresponds to $93 \%$ of its ultimate strain, indicating that this strengthening technique can mobilize stress levels in the CFRP reinforcing elements close to the tensile strength of this advanced composite material (high effectiveness of the NSM technique for the flexural strengthening of $\mathrm{RC}$ beams).

- The failure mode of the NSM beams depends on the percentage of the CFRP. The strengthened beam with the lowest CFRP percentage (beam S1L) failed by the rupture of the CFRP after the yielding of the tensile steel reinforcements. The strengthened beams with the intermediate (beam S2L) and the highest (beam S3L) CFRP percentage failed by the detachment of the CFRP after the yielding of the tensile steel reinforcements. The detachment of the CFRP in the S2L beam occurred near the rupture of the CFRP $\left(\varepsilon_{C F R P}^{\max }=17.4 \%\right.$ ) and took longer to occur than the detachment of the CFRP in the S3L beam, where the value of $\varepsilon_{C F R P}^{\max }$ was $14.9 \%$. Based on these results, by increasing the percentage of the CFRP, the strain in the CFRP laminates at failure decreases which shows that by increasing the percentage of the CFRP, the probability of using more capacity of CFRP laminates decreases.

Taking into account the results obtained in the tested beams, the performance of the analytical formulation proposed by ACI for the prediction of the flexural strength of a RC member using NSM technique with CFRP laminates was appraised. Regardless of the method to obtain the value of the the maximum strain that can be applied to the NSM CFRP laminates $\left(\varepsilon_{f d}\right)$, the ACI formulation provided safe results. However, the equation proposed by Barros et al. (2007) to estimate the value of $\varepsilon_{f d}$ assured results closest to the experimental ones.

A numerical strategy was used to evaluate the load-deflection of the tested RC beams. Using the properties of the intervening materials in the tested beams, obtained from experimental tests, the relationship between the force and the mid-span deflection recorded in the tested beams was predicted with high accuracy, revealing that the adopted numerical strategy is appropriate to simulate the behavior of RC beams flexurally strengthened using NSM technique with CFRP laminates. Finally, a parametric study was conducted to assess the influence of the percentage of longitudinal bars $\left(\rho_{s l}\right)$, the percentage of CFRP ( $\left.\rho_{f}\right)$ and the concrete strength $\left(f_{c k}\right)$ on the flexural strengthening performance of the NSM technique. For the flexural strengthening performance in terms of maximum load $\left(\Delta F_{\max }\right)$, this study has demonstrated that $\Delta F_{\max }$ decreases significantly with $\rho_{s l}$ and is almost insensitive to the $f_{c k}$. These results support the assumptions subjacent to the equation (6) for the evaluation of the maximum tensile strain that should be adopted for the CFRP laminates when predicting the flexural capacity of a RC element flexurally strengthened according to the NSM technique. 


\section{ACKNOWLEDGEMENTS}

The authors wish to acknowledge the materials provided by $\mathrm{S} \& \mathrm{P} \circledast$ and Secil (Unibetão, Braga). This work was supported by FEDER funds through the Operational Program for Competitiveness Factors - COMPETE and National Funds through FCT - Portuguese Foundation for Science and Technology under the project PTDC/ECM-EST/1882/2014. The second author wish to acknowledge the grant SFRH/BSAB/114302/2016 provided by FCT.

\section{REFERENCES}

[1] ACI Committee 440, 2008, "Guide for the design and construction of externally bonded FRP systems for strengthening concrete structures", ACI 440.2R-08, American Concrete Institute, Farmington Hills, Mich (2008).

[2] fib - Bulletin 14, "Externally bonded FRP reinforcement for RC structures”, Technical report by Task Group 9.3 FRP (Fiber Reinforced Polymer) reinforcement for concrete structures, Féderation Internationale du Béton - fib, July, 130 pp. (2001).

[3] Bakis, C.E., Bank, L.C., Brown, V.L., Cosenza, E., Davalos, J.F., Lesko, J.J., Machida, A., Riskalla, S.H. and Triantafillou, T.C., "Fiber-reinforced polymer composites for construction - state-of-the-art review”, Journal of Composites for Construction, 6(2), 73-87 (2002).

[4] Rahimi, H. and Hutchinson A., "Concrete beams strengthened with externally bonded FRP plates", Journal of Composites for Construction, Volume 5, Issue 1, pp. 44-56 (2001).

[5] M.R. Esfahani, M.R. Kianoush and A.R. Tajari, "Flexural behaviour of reinforced concrete beams strengthened by CFRP sheets”, Engineering Structures, Volume 29, Issue 10, October, pp. 2428-2444 (2007).

[6] Barros, J.A.O., Dias, S.J.E. and Lima J.L.T., "Efficacy of CFRP-based techniques for the flexural and shear strengthening of concrete beams", Journal Cement \& Concrete Composites, Volume 29, Issue 3, March, pp. 203217 (2007).

[7] Bilotta, A., Ceroni, F., Nigro, E. and Pecce, M., “Efficiency of CFRP NSM strips and EBR plates for flexural strengthening of RC beams and loading pattern influence”, Composite Structures Journal, Volume 124, May, pp. $163-175$ (2015).

[8] El-Hacha, R. and Riskalla, S.H., "Near-surface-mounted fiber-reinforced polymer reinforcements for flexural strengthening of concrete structures”, ACI Structural Journal, 101(5), 717-726 (2004).

[9] Carolin, A., "Carbon fibre reinforced polymers for strengthening of structural elements", PhD Thesis, Division of Structural Engineering, Luleå University of Technology, Lulea, Sweden, 190 pp. (2003).

[10] Barros, J.A.O. and Fortes, A.S., "Flexural strengthening of concrete beams with CFRP laminates bonded into slits", Journal Cement and Concrete Composites, 27(4) p. 471-480 (2005). 
[11] Kotynia, R., “Analysis of the flexural response of NSM FRP-strengthened concrete beams”, $8^{\text {th }}$ International Symposium on Fiber Reinforced Polymer (FRP) Reinforcement for Concrete Structures (FRPRCS-8), Patras, Greece, July 16-18 (2007).

[12] De Lorenzis, L. and Teng J.G., "Near-surface mounted FRP reinforcement: An emerging technique for strengthening structures”, Composites Part B Journal, 38, pp. 119-143 (2007).

[13] Capozucca, R., "Static and dynamic response of damaged RC beams strengthened with NSM CFRP rods", Composite Structures Journal, 91, p. 237-248 (2009).

[14] Capozucca, R., "Analysis of bond-slip effects in RC beams strengthened with NSM CFRP rods”, Composite Structures Journal, 102, p. 143-155 (2013).

[15] Sharaky, I.A., Torres, L., Sallam, H.E.M., "Experimental and analytical investigation into the flexural performance of RC beams with partially and fully bonded NSM FRP bars/strips”, Composite Structures Journal, 122, p. 113-126 (2015).

[16] Costa, I.G. and Barros, J.A.O., "Flexural and shear strengthening of RC beams with composite materials - the influence of cutting steel stirrups to install CFRP strips”, Journal Cement and Concrete Composites, 32, p. 544$553(2010)$.

[17] Coelho, M.R.F., Sena-Cruz, J.M. and Neves, L.A.C., “A review on the bond behavior of FRP NSM systems in concrete”, Construction and Building Materials Journal, 93, p. 1157-1169 (2015).

[18] EN 206-1, “Concrete - Part 1: Specification, performance, production and conformity”, European standard, CEN, 69 pp. (2000).

[19] EN 10002-1, “Metallic materials - Tensile testing. Part 1: Method of test (at ambient temperature)”, European Standard, CEN, Brussels, Belgium, 35 pp. (1990).

[20] ISO 527-5, "Plastics - Determination of tensile properties - Part 5: Test conditions for unidirectional fibrereinforced plastic composites”, International Organization for Standardization (ISO), Geneva, Switzerland, 9 pp. (1997).

[21] Costa, I.G. and Barros, J.A.O., "Tensile creep of a structural epoxy adhesive: experimental and analytical characterization”, International Journal of Adhesion \& Adhesives, 59, 115-124 (2015).

[22] ISO 527-2, "Plastics - Determination of tensile properties - Part 2: Test conditions for moulding and extrusion plastics", International Organization for Standardization, 1993.

[23] Barros, J.A.O., Taheri, M., Salehian, H. and Mendes P.J.D., “A design model for fibre reinforced concrete beams pre-stressed with steel and FRP bars", Composite Structures, 94, 2494-2512 (2012).

[24] Barros, J.A.O., Oliveira, J.T., Lourenço, P.J.B., Bonaldo, E., "Flexural behavior of reinforced masonry panels", ACI Structural Journal, 103(3), May, pp. 418-426 (2006). 
[25] CEB-FIP Model Code. Comite Euro-International du Beton, Bulletin d'Information n 213/214 (1993).

[26] EN 1992-1-1, "Eurocode2: Design of Concrete Structures Parte 1-1: General Rules for Buildings", CEN, Brussels, Belgium (2004).

[27] Sena-Cruz, J.M., "Strengthening of concrete structures with near-surface mounted CFRP laminate strips”, PhD thesis, University of Minho (2004).

\section{TABLES AND FIGURES}

\section{List of Tables:}

Table 1 - General information of the tested RC beams.

Table 2 - Values of the properties of the intervening materials.

Table 3 - Summary of the results in terms of loads and deflections.

Table 4 - Strain values in the CFRP laminates and mobilization level of the CFRP.

Table 5 - Experimental versus analytical values.

Table 6 - Properties of the steel bars used in the numerical simulation.

\section{List of Figures:}

Fig. 1 - Geometry of the type of beam, steel reinforcements common to all beams, support and load conditions (dimensions in $\mathrm{mm})$.

Fig. 2 - RC beams strengthened with NSM CFRP laminates (dimensions in mm).

Fig. 3 - Test set up and the beam S3L with 3 NSM CFRP laminates immediately before the start of the test until failure.

Fig.4 - Positions of the: a) five displacement transducers (LVDT1 to LVDT5); b) three strain gauges in the longitudinal tensile bars (SGS1 to SGS3); c) five strain gauges in the monitored NSM CFRP laminates (SGL1 to SGL5) (dimensions in $\mathrm{mm}$ ).

Fig. 5 - Force vs. deflection at mid-span of the tested RC beams.

Fig. 6 - Effect of the CFRP percentage on the effectiveness of the NSM technique with CFRP laminates for the flexural strengthening of RC beams in terms of: a) yielding load and maximum load; b) ductility.

Fig. 7 - Cracking patterns of the tested RC beams.

Fig. 8 - Failure modes of the tested RC beams.

Fig. 9 - Force vs. strain in the longitudinal steel bars and in the monitored CFRP laminates (see also Fig. 4).

Fig. 10 - CFRP strain curves and average shear stress (see also Fig. 4). 
Fig. 11 - Comparison between the experimental and analytical values of the maximum load of the tested NSM beams.

Fig. 12 - Concrete laws used in the numerical simulation: a) in compression [23]; b) in tension [10].

Fig. 13 - Stress-strain relationship for the: a) steel bars [10]; b) CFRP laminates.

Fig. 14 - Experimental vs. numerical force-deflection at mid-span for the tested RC beams: a) REF; b) S1L; c) S2L; d) S3L.

Fig. 15 - Influence of the $\rho_{s l}, \rho_{f}$ and $f_{c k}$ on the NSM flexural strengthening performance in terms of load carrying capacity at serviceability limit state conditions, $\Delta F_{S L S}$.

Fig. 16 - Influence of the $\rho_{s l}, \rho_{f}$ and $f_{c k}$ on the NSM flexural strengthening performance in terms of load carrying capacity at yield initiation of the existing flexural steel reinforcement, $\Delta F_{s y}$.

Fig. 17 - Influence of the $\rho_{s l}, \rho_{f}$ and $f_{c k}$ on the NSM flexural strengthening performance in terms of maximum load, $\Delta F_{\max }$. 
Table 1 - General information of the tested RC beams.

\begin{tabular}{|c|c|c|c|}
\hline \multirow[b]{2}{*}{ Beam } & \multirow{2}{*}{$\begin{array}{c}\rho_{s l} \\
(\%)^{(\mathrm{a})}\end{array}$} & \multicolumn{2}{|c|}{ NSM CFRP flexural strengthening } \\
\hline & & Quantity & $\begin{array}{c}\rho_{f} \\
(\%)^{(\mathrm{b})}\end{array}$ \\
\hline REF & \multirow{4}{*}{0.38} & - & - \\
\hline S1L & & 1 CFRP laminate $\left(A_{f}=1 \times 1.4 \times 10=14 \mathrm{~mm}^{2}\right)$ & 0.03 \\
\hline $\mathrm{S} 2 \mathrm{~L}$ & & 2 CFRP laminates $\left(A_{f}=2 \times 1.4 \times 10=28 \mathrm{~mm}^{2}\right)$ & 0.06 \\
\hline $\mathrm{S} 3 \mathrm{~L}$ & & 3 CFRP laminates $\left(A_{f}=3 \times 1.4 \times 10=42 \mathrm{~mm}^{2}\right)$ & 0.09 \\
\hline
\end{tabular}

(a) The percentage of the longitudinal tensile reinforcement was obtained from $\rho_{s l}=\left(A_{s l} /\left(b_{w} \times d\right)\right) \times 100$, where $A_{s l}$ is the cross sectional area of the longitudinal tensile steel reinforcement (see Fig. 1), $b_{w}=150 \mathrm{~mm}$ is the width of the beam's cross section, and $d$ is the distance from extreme concrete compression fibre to the centroid of tensile reinforcement. ${ }^{(b)}$ The CFRP percentage was obtained from $\rho_{f}=\left(A_{f} / A_{c}\right) \times 100$, where $A_{f}$ is the cross sectional area of the NSM CFRP laminates and $A_{c}$ is the concrete cross sectional area.

Table 2 - Values of the properties of intervening materials.

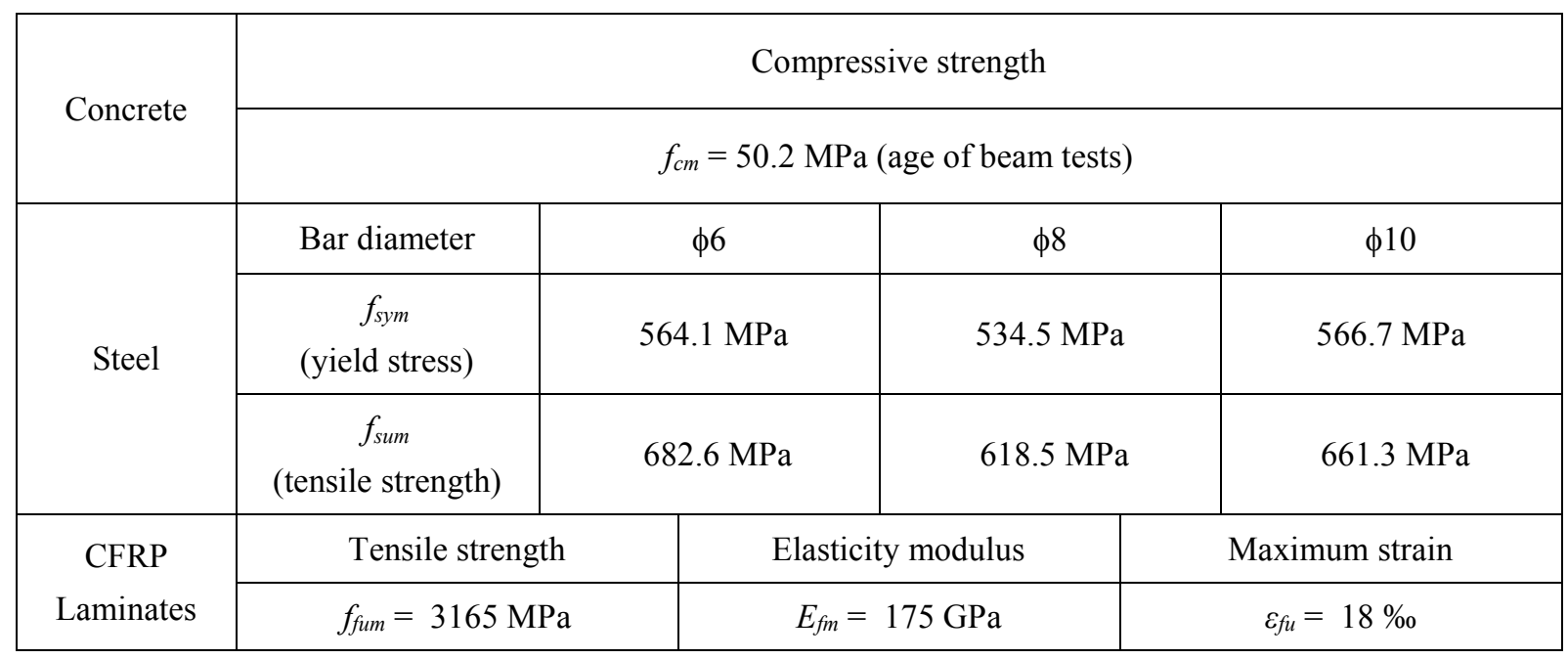


Table 3 - Summary of the results in terms of loads and deflections.

\begin{tabular}{|c|c|c|c|c|c|c|c|c|}
\hline \multirow[b]{2}{*}{ Beam } & \multicolumn{2}{|r|}{ Cracking } & \multicolumn{3}{|c|}{ Yielding } & \multicolumn{3}{|c|}{ Maximum } \\
\hline & $\begin{array}{l}F_{\text {crak }} \\
(\mathrm{kN})\end{array}$ & $\frac{F_{c r a k}^{S t r}-F_{c r a k}^{R e f}}{F_{c r a k}^{R e f}} \times 100$ (a) & $\begin{array}{c}F_{s y} \\
(\mathrm{kN})\end{array}$ & $\frac{F_{s y}^{S t r}-F_{s y}^{\operatorname{Ref}}}{F_{s y}^{\operatorname{Ref}}} \times 100$ & $\begin{array}{c}u_{F s y} \\
(\mathrm{~mm})\end{array}$ & $\begin{array}{l}F_{\max } \\
(\mathrm{kN})\end{array}$ & $\frac{F_{\max }^{S t r}-F_{\max }^{\operatorname{Ref}}}{F_{\max }^{\operatorname{Ref}}} \times 100$ (c) & $\begin{array}{l}u_{\text {Fmax }} \\
(\mathrm{mm})\end{array}$ \\
\hline REF & 20.1 & - & 56.6 & - & 8.3 & 62.3 & - & 45.1 \\
\hline S1L & 21.0 & 4.5 & 62.4 & 10.2 & 8.5 & 88.4 & 41.9 & 41.2 \\
\hline $\mathrm{S} 2 \mathrm{~L}$ & 22.2 & 10.5 & 69.5 & 22.8 & 9.4 & 111.9 & 79.6 & 43.6 \\
\hline S3L & 24.0 & 19.4 & 76.0 & 34.3 & 9.7 & 126.6 & 103.2 & 38.9 \\
\hline
\end{tabular}

(a) $F_{c r a k}^{R e f}$ and $F_{c r a k}^{S t r}$ are the cracking loads of the reference and the NSM CFRP strengthened beam, respectively. (b) $F_{s y}^{R e f}$ and $F_{s y}^{S t r}$ are the yielding loads of the reference and the NSM CFRP strengthened beam, respectively. ${ }^{(c)} F_{\max }^{R e f}$ and $F_{\max }^{S t r}$ are the maximum loads of the reference and the NSM CFRP strengthened beam, respectively.

Table 4 - Strain values in the CFRP laminates and mobilization level of the CFRP.

\begin{tabular}{|c|c|c|c|c|c|c|c|c|}
\hline Beam & $\begin{array}{c}\varepsilon_{C F R P}^{S G L 1} \\
(\% \mathrm{o})\end{array}$ & $\begin{array}{c}\varepsilon_{C F R P}^{S G L 2} \\
(\% \text { o) }\end{array}$ & $\begin{array}{c}\varepsilon_{C F R P}^{S G L 3} \\
(\%)\end{array}$ & $\begin{array}{c}\varepsilon_{C F R P}^{S G L 4} \\
(\%)\end{array}$ & $\begin{array}{c}\varepsilon_{C F R P}^{S G L 5} \\
(\%)\end{array}$ & $\begin{array}{c}\varepsilon_{C F R P}^{\max } \\
(\% \text { o) }\end{array}$ & $\begin{array}{c}\text { Mobilization level } \\
\text { of the CFRP } \\
\text { (\%) }\end{array}$ & Failure mode \\
\hline S1L & 17.8 & 17.9 & 17.1 & 4.7 & 0.2 & 17.9 & 100 & $\begin{array}{l}\text { CFRP } \\
\text { rupture }\end{array}$ \\
\hline S2L & 17.1 & 17.4 & 15.9 & 8.0 & 0.2 & 17.4 & 97 & $\begin{array}{c}\text { CFRP } \\
\text { detachment }\end{array}$ \\
\hline S3L & 14.3 & 14.9 & 13.6 & 10.2 & 0.2 & 14.9 & 83 & $\begin{array}{c}\text { CFRP } \\
\text { detachment }\end{array}$ \\
\hline
\end{tabular}

\footnotetext{
${ }^{(a)}$ Mobilization level of the CFRP $=\left(\varepsilon_{C F R P}^{\max } / \varepsilon_{f u}\right)$, where $\varepsilon_{f u}=18 \%$ (see Table 2).
} 
Table 5 - Experimental versus analytical values.

\begin{tabular}{|c|c|c|c|c|c|c|c|c|c|c|}
\hline \multirow[t]{2}{*}{ Beam } & \multicolumn{2}{|c|}{ Experimental } & \multicolumn{4}{|c|}{$\begin{array}{l}\text { Proposal of ACI Committee } 440 \text { for the strain } \varepsilon_{f d} \\
\qquad\left[\varepsilon_{f d}=0.7 \times \varepsilon_{f u}\right] \text { (equation (5)) }\end{array}$} & \multicolumn{4}{|c|}{$\begin{array}{c}\text { Proposal of Barros et al. [8] for the strain } \varepsilon_{f d} \\
{\left[\varepsilon_{f d}=\left(-32.648 \times \rho_{s l, e q}+0.9606\right) \times \varepsilon_{f u}\right]} \\
\text { (equation (6)) }\end{array}$} \\
\hline & $\begin{array}{l}F_{\max }^{\exp } \\
(\mathrm{kN})\end{array}$ & $\begin{array}{l}M_{\max }^{\exp \text { (a) }} \\
(\mathrm{kN.m})\end{array}$ & $\begin{array}{l}\varepsilon_{f d} \\
(\% \mathrm{o})\end{array}$ & $\begin{array}{c}M_{\max }^{\text {ana }} \\
(\mathrm{kN} . \mathrm{m})\end{array}$ & $\begin{array}{c}F_{\max }^{a n a} \\
(\mathrm{kN})^{(\mathrm{b})}\end{array}$ & $F_{\max }^{\exp } / F_{\max }^{\text {ana }}$ & $\begin{array}{c}\varepsilon_{f d} \\
(\%)\end{array}$ & $\begin{array}{c}M_{\max }^{\text {ana }} \\
(\mathrm{kN} . \mathrm{m})\end{array}$ & $\begin{array}{c}F_{\max }^{\text {ana }} \\
(\mathrm{kN})^{(\mathrm{b})}\end{array}$ & $F_{\max }^{\exp } / F_{\max }^{\text {ana }}$ \\
\hline $\mathrm{S} 1 \mathrm{~L}$ & 88.4 & 39.8 & 12.6 & 31.66 & 70.4 & 1.26 & 14.84 & 33.26 & 73.9 & 1.20 \\
\hline S2L & 111.9 & 50.36 & 12.6 & 40.15 & 89.2 & 1.25 & 14.68 & 43.04 & 95.6 & 1.17 \\
\hline S3L & 126.6 & 56.97 & 12.6 & 48.55 & 107.9 & 1.17 & 14.51 & 52.47 & 116.6 & 1.09 \\
\hline
\end{tabular}

(a) $M_{\max }^{\exp }=0.45 \times F_{\max }^{\exp } \cdot{ }^{\text {(b) }} F_{\max }^{a n a}=M_{\max }^{\operatorname{ana}} / 0.45$.

Table 6 - Properties of the steel bars used in the numerical simulation.

\begin{tabular}{|c|c|c|c|c|c|c|c|c|}
\hline $\begin{array}{c}\text { Bar diameter } \\
(\mathrm{mm})\end{array}$ & $\begin{array}{c}E_{S} \\
(\mathrm{GPa})\end{array}$ & $\begin{array}{c}\varepsilon_{s} 1 \\
(\mathrm{~mm} / \mathrm{mm})\end{array}$ & $\begin{array}{c}\sigma_{s 1} \\
(\mathrm{MPa})\end{array}$ & $\begin{array}{c}\varepsilon_{s 2} \\
(\mathrm{~mm} / \mathrm{mm})\end{array}$ & $\begin{array}{c}\sigma_{s 2} \\
(\mathrm{MPa})\end{array}$ & $\begin{array}{c}\varepsilon_{s 3} \\
(\mathrm{~mm} / \mathrm{mm})\end{array}$ & $\begin{array}{c}\sigma_{s 3} \\
(\mathrm{MPa})\end{array}$ & $\mathrm{P}$ \\
\hline 8,10 & 190 & 0.002983 & 566.7 & 0.01 & 566.7 & 0.10 & 661.3 & 3 \\
\hline
\end{tabular}




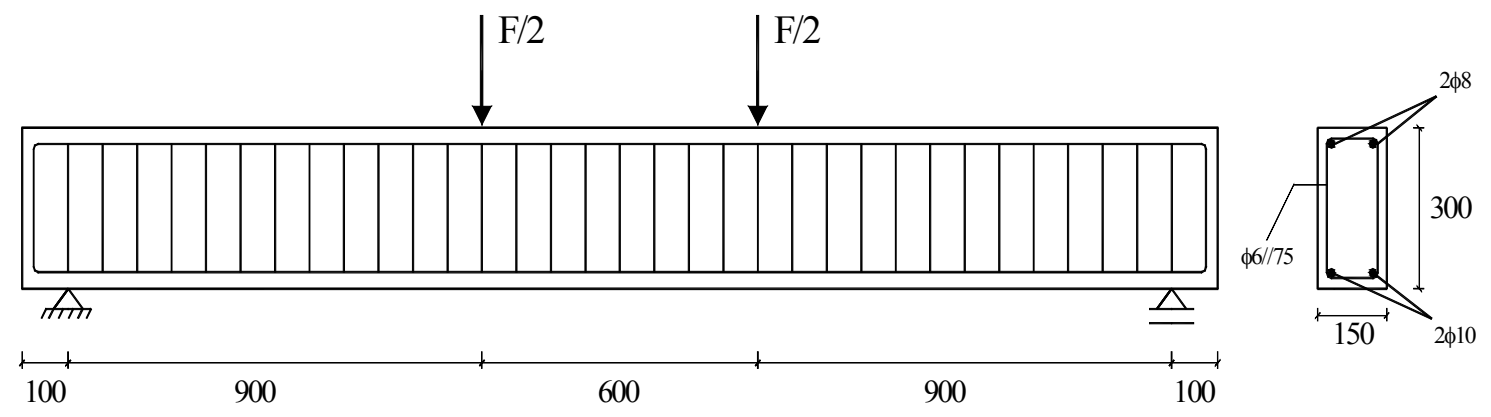

Fig. 1 - Geometry of the type of beam, steel reinforcements common to all beams, support and load conditions (dimensions in $\mathrm{mm}$ ). 


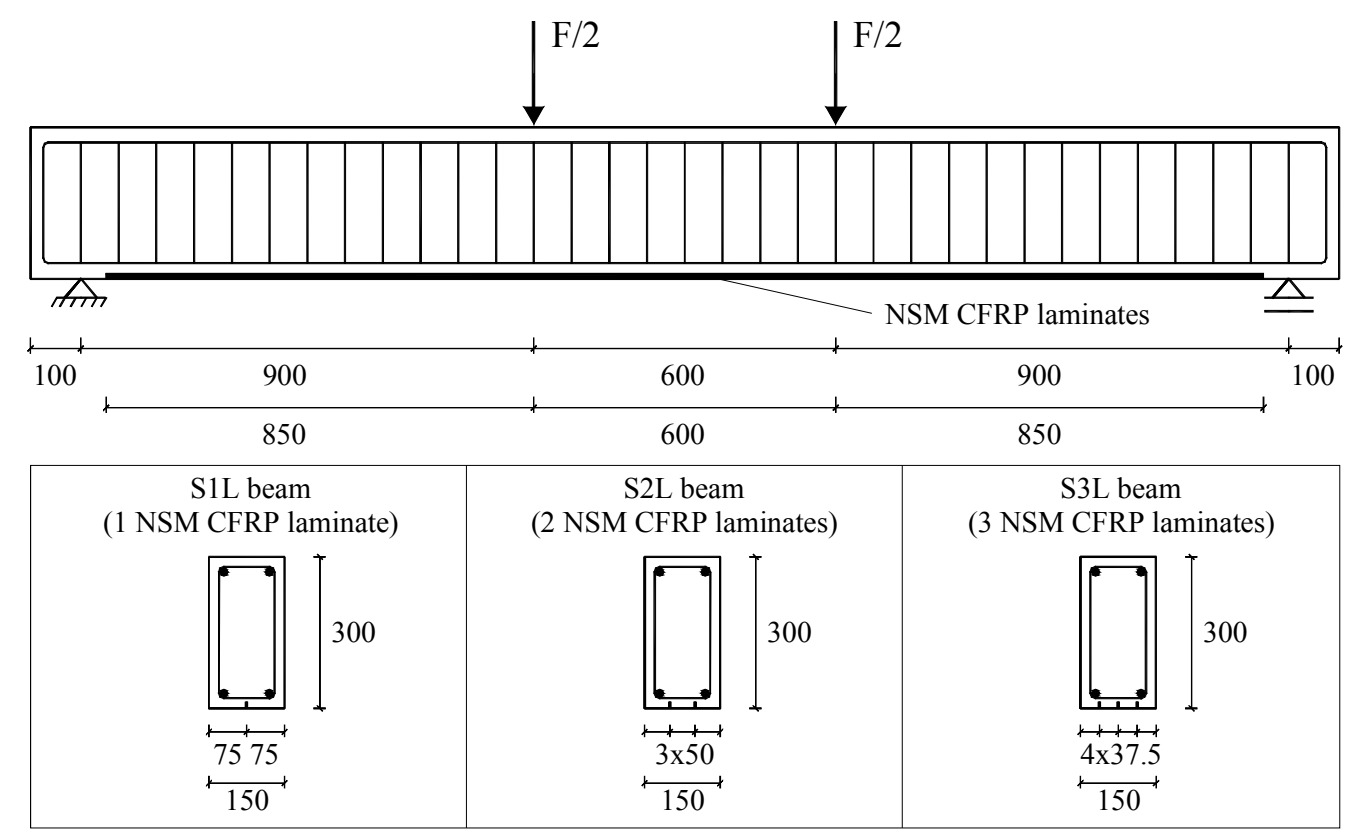

Support line

Bottom view of the S1L beam (1 NSM CFRP laminate)

Support line

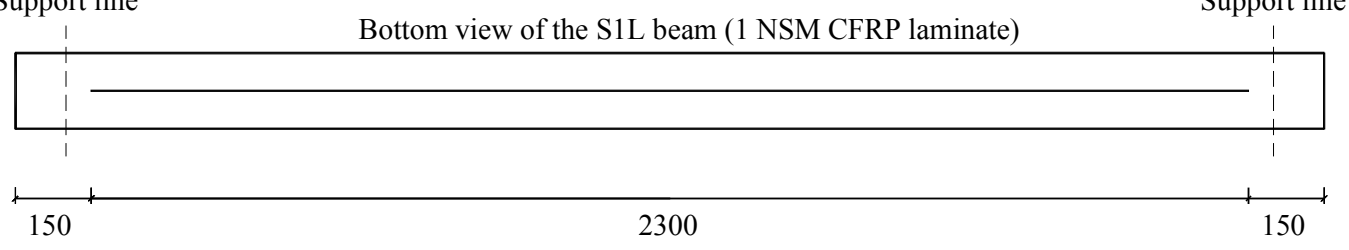

Support line

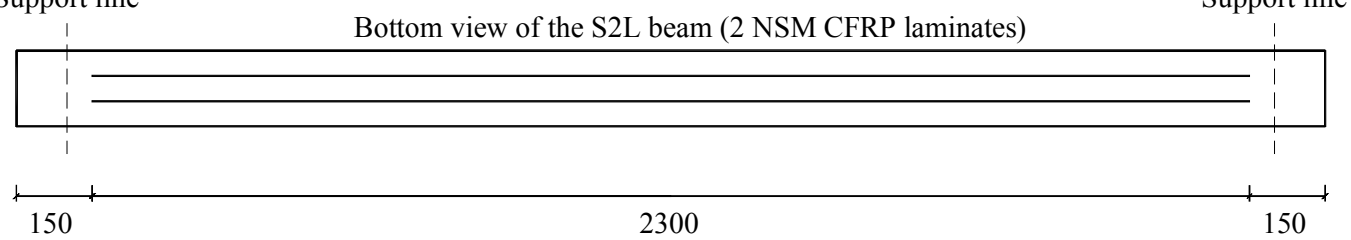

Support line

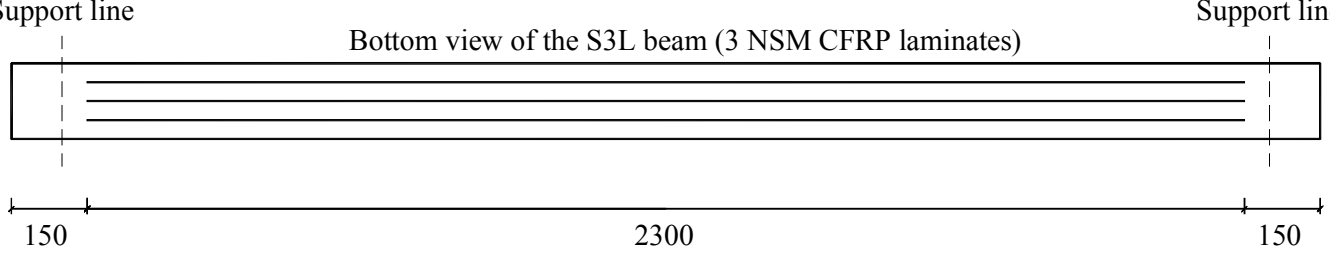

Fig. 2 - RC beams strengthened with NSM CFRP laminates (dimensions in mm). 

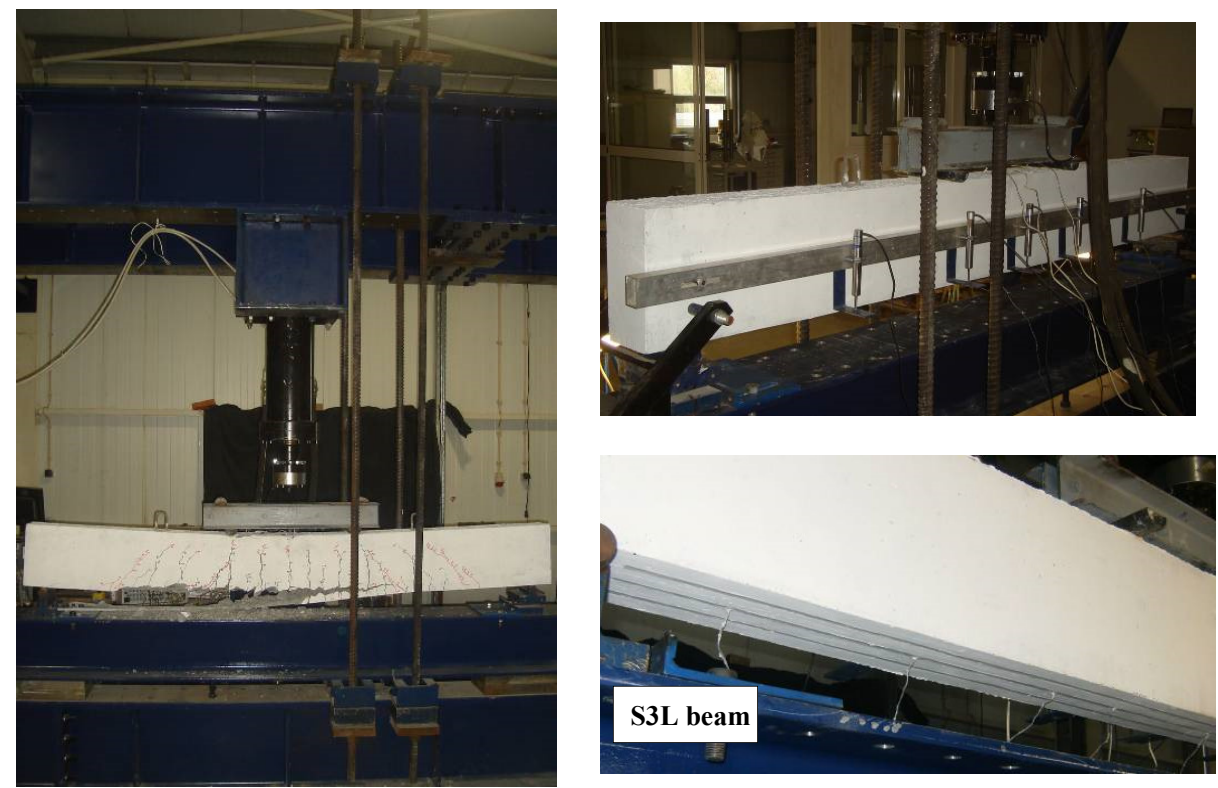

Fig. 3 - Test set up and the beam S3L with 3 NSM CFRP laminates immediately before the start of the test until failure.

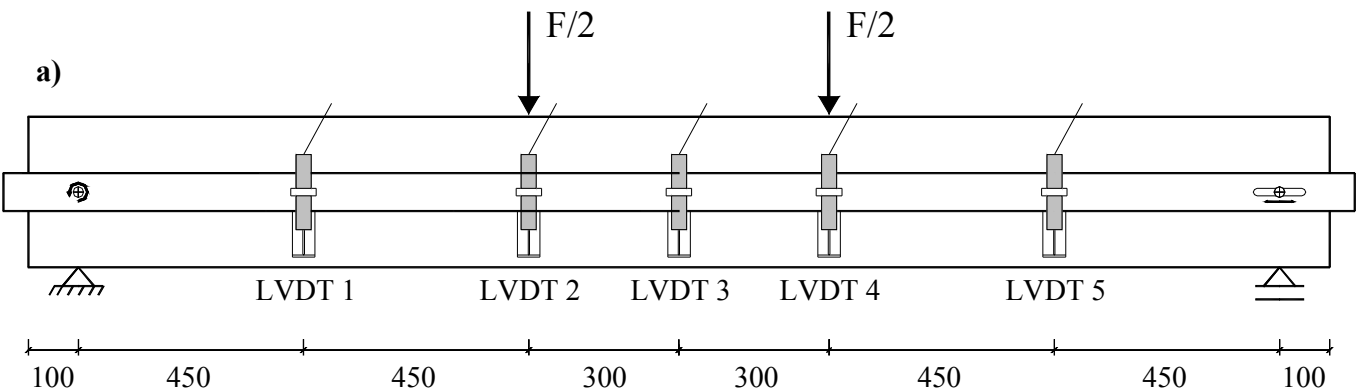

b)
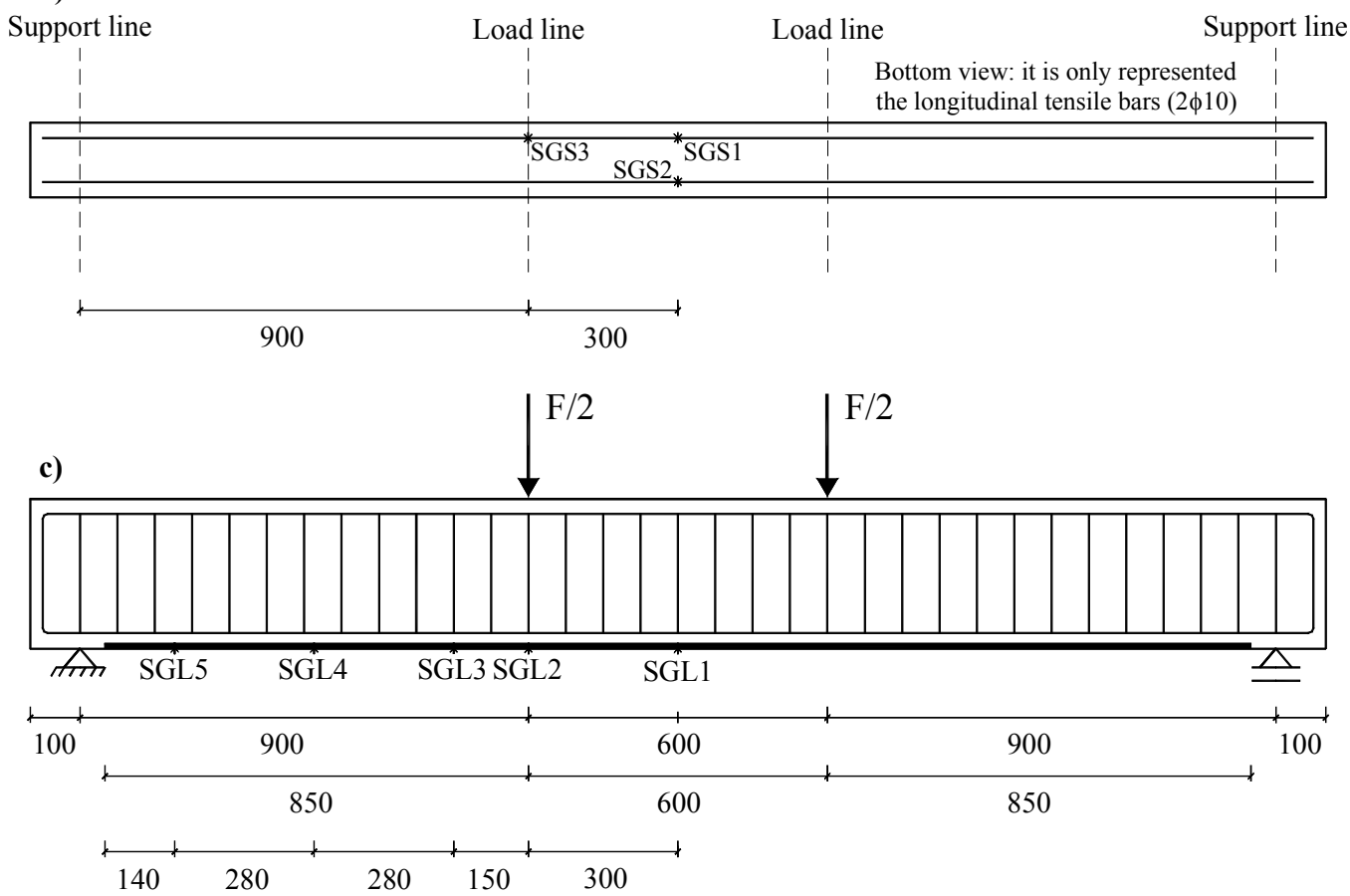

Fig. 4 - Positions of the: a) five displacement transducers (LVDT1 to LVDT5); b) three strain gauges in the longitudinal tensile bars (SGS1 to SGS3); c) five strain gauges in the monitored NSM CFRP laminates (SGL1 to SGL5) (dimensions in $\mathrm{mm}$ ). 


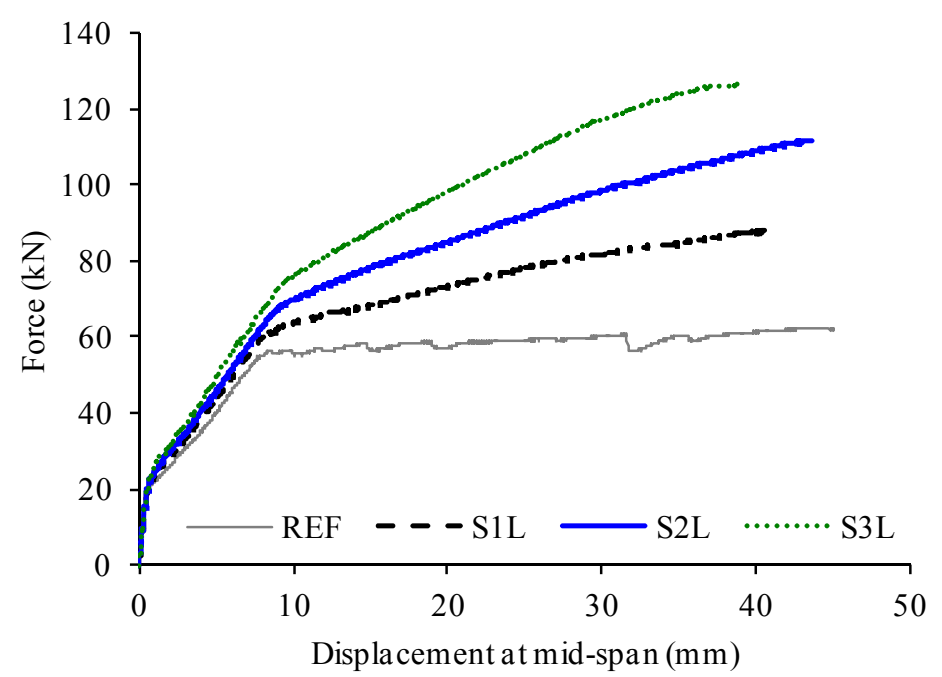

Fig. 5 - Force $v s$. deflection at mid-span of the tested RC beams.

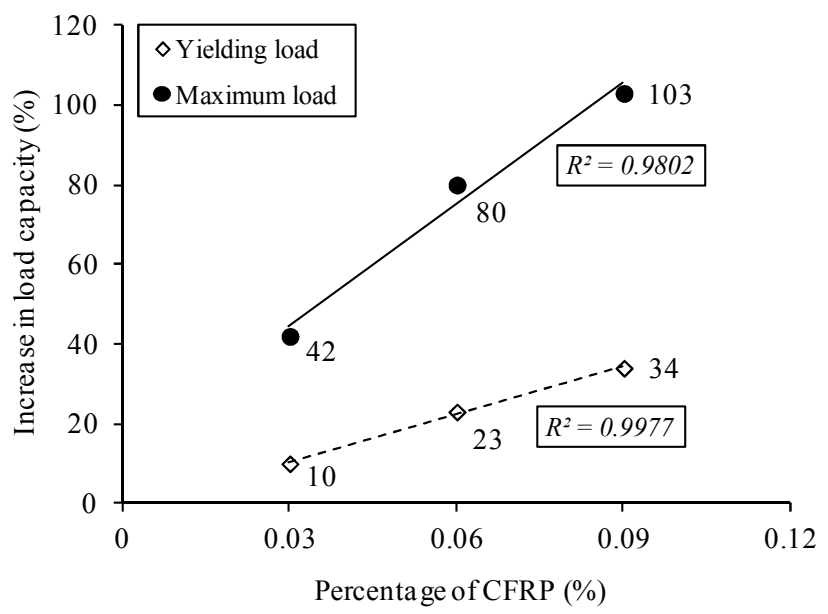

a)

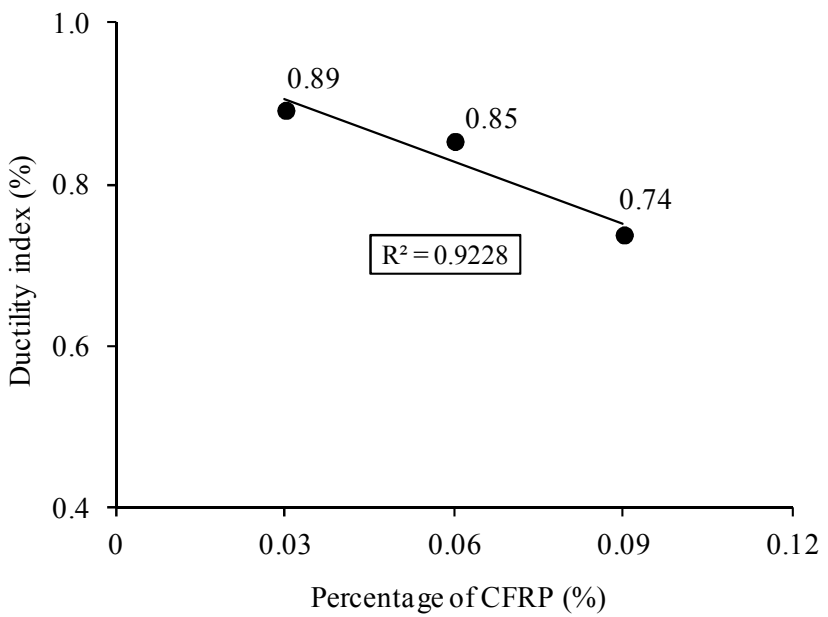

b)

Fig. 6 - Effect of the CFRP percentage on the effectiveness of the NSM technique with CFRP laminates for the flexural strengthening of RC beams in terms of: a) yielding load and maximum load; b) ductility. 


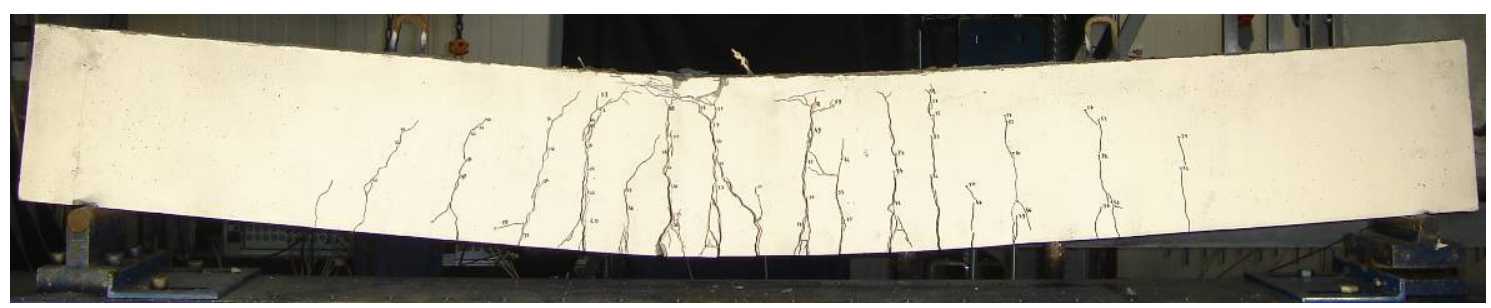

Non-strengthened RC beam (REF beam)

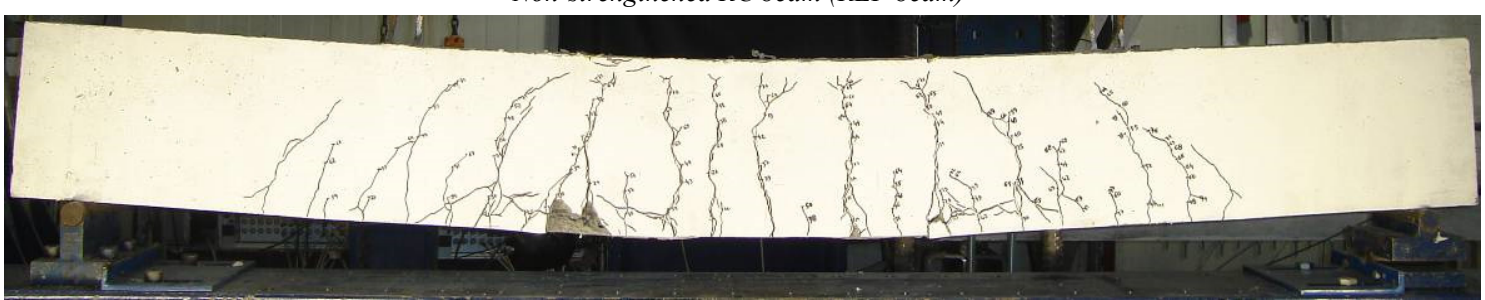

RC beam flexurally strengthened with one CFRP laminates (S1L beam)

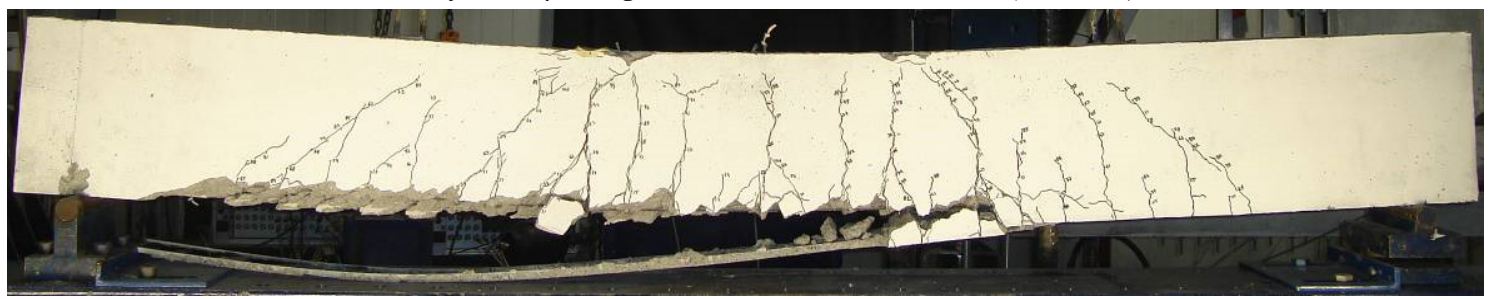

$R C$ beam flexurally strengthened with two CFRP laminates ( $S 2 L$ beam)

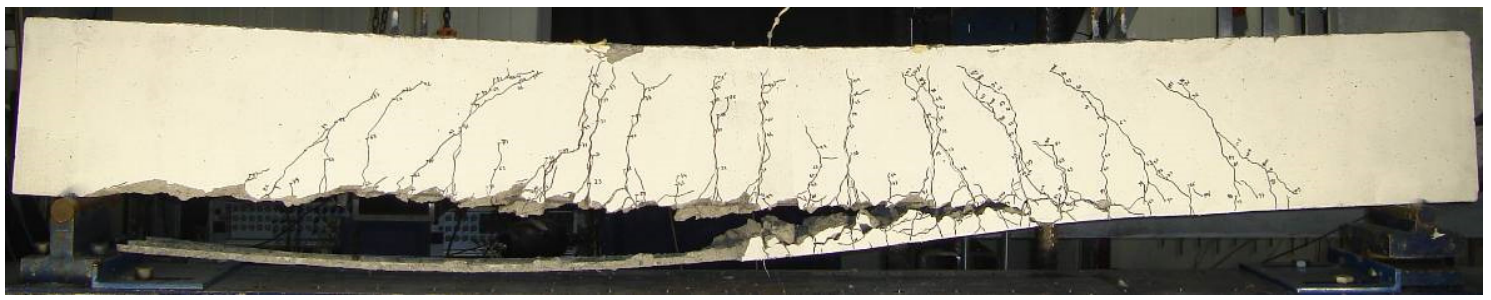

$R C$ beam flexurally strengthened with three CFRP laminates (S3L beam)

Fig. 7 - Cracking patterns of the tested RC beams. 


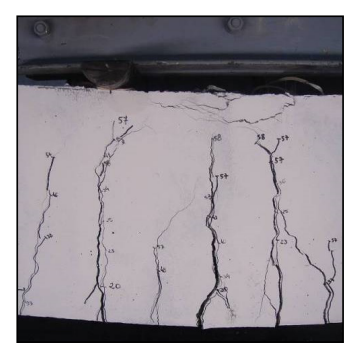

a) Concrete crushing in the reference $R C$ beam ( $R E F$ beam)

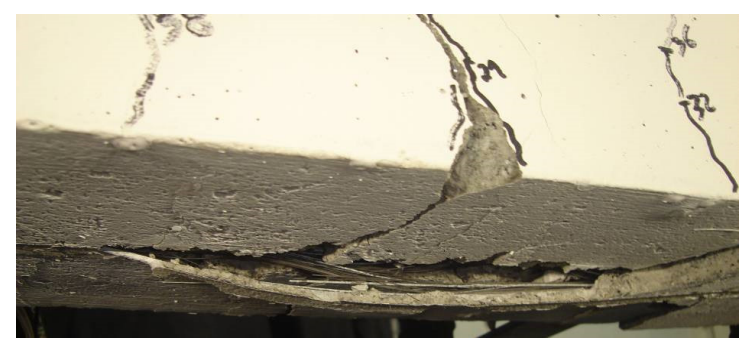

b) Rupture of the CFRP in the beam strengthened with one NSM CFRP laminate (S1L beam)
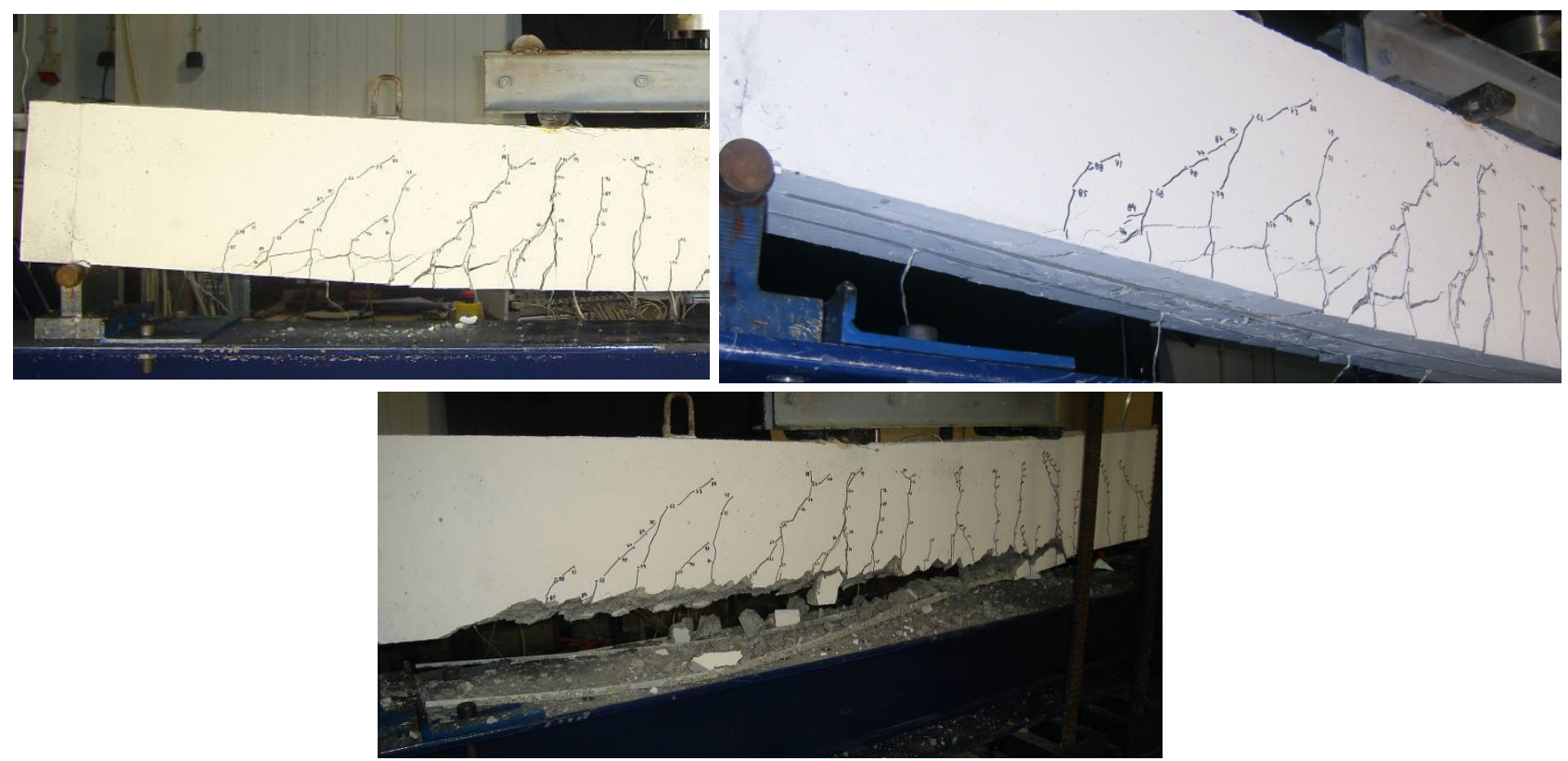

c) Detachment of the CFRP in the beams strengthened with two NSM CFRP laminates (S2L beam)
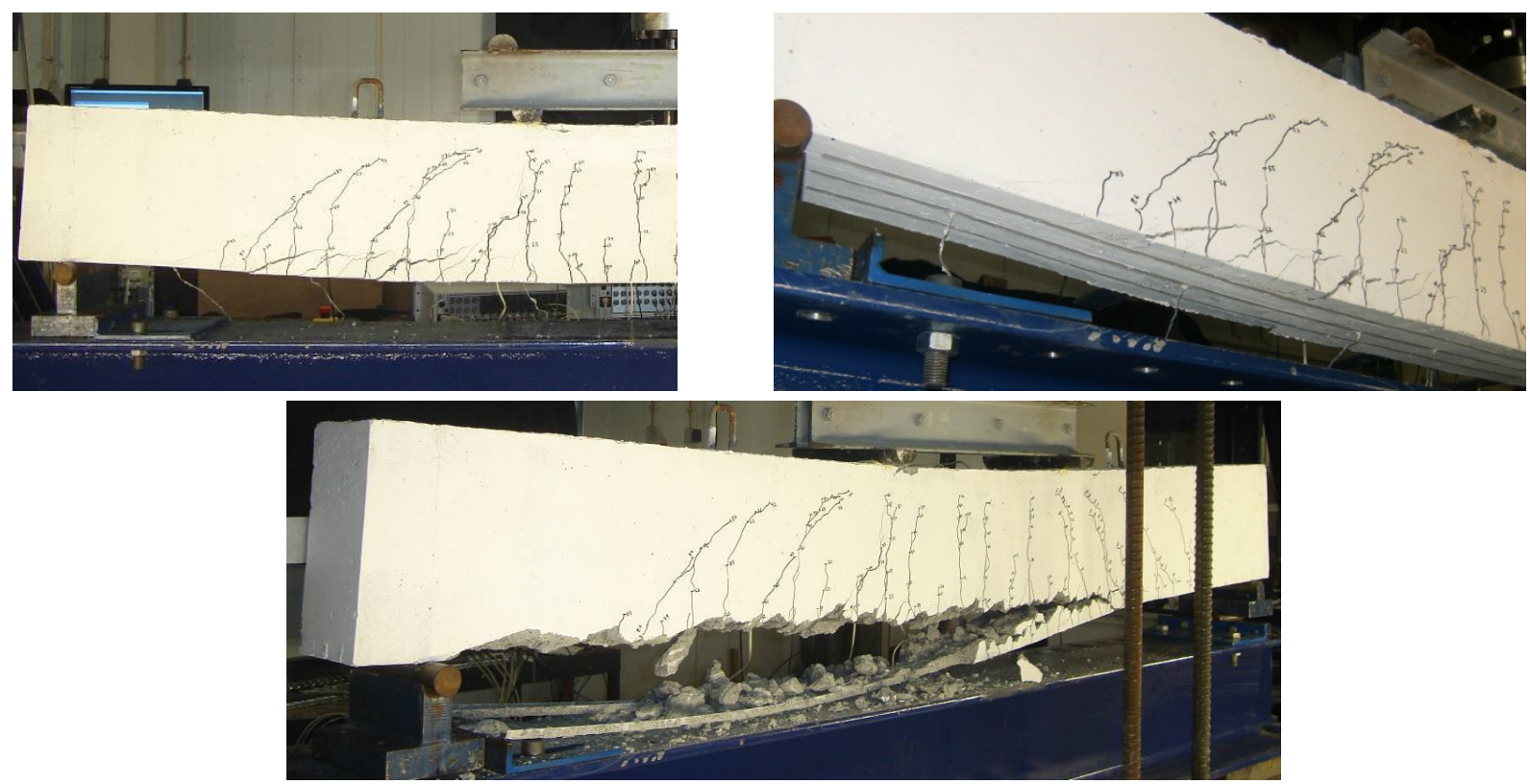

d) Detachment of the CFRP in the beams strengthened with three NSM CFRP laminates (S3L beam)

Fig. 8 - Failure modes of the tested RC beams. 


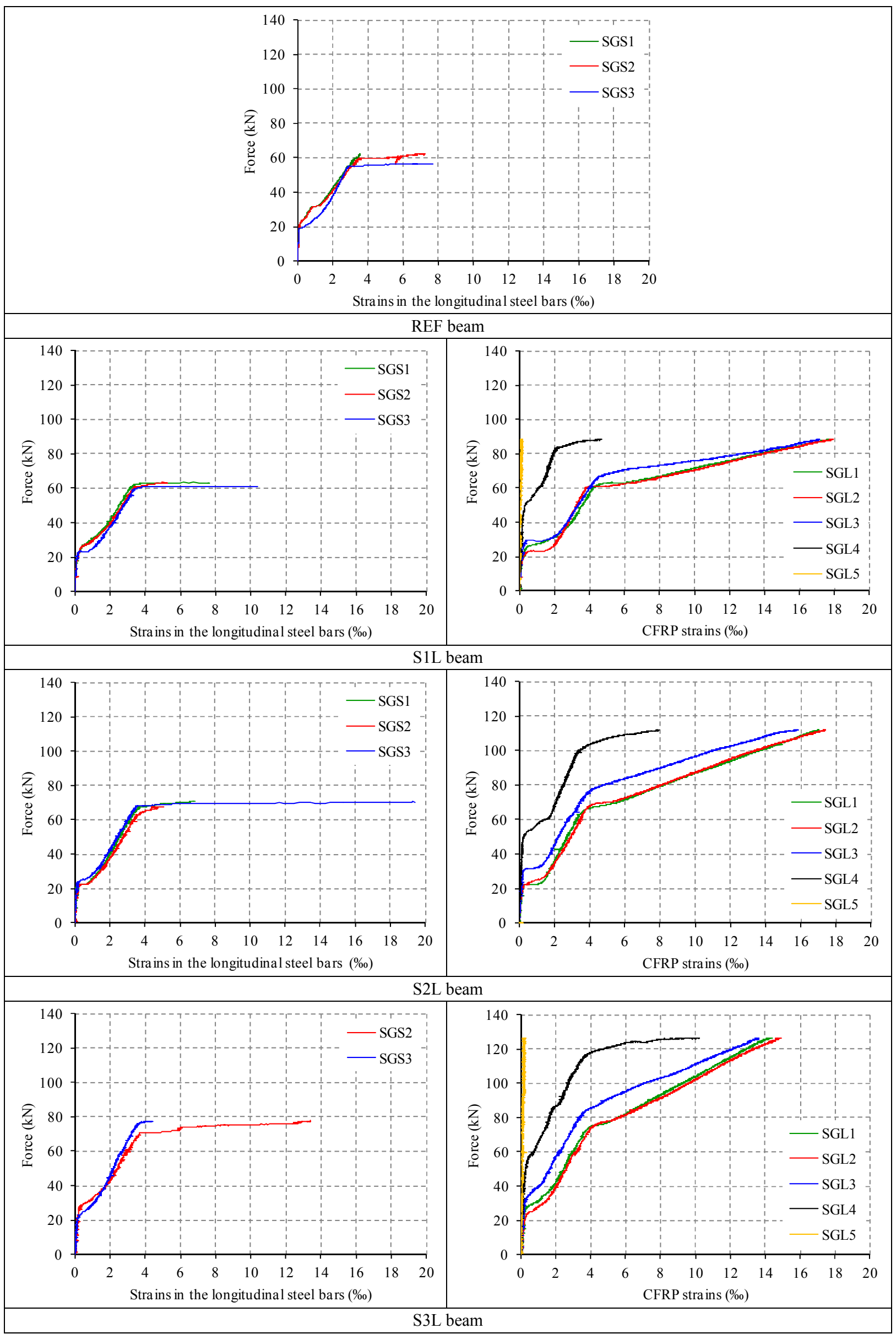

Fig. 9 - Force vs. strain in the longitudinal steel bars and in the monitored CFRP laminates (see also Fig. 4). 


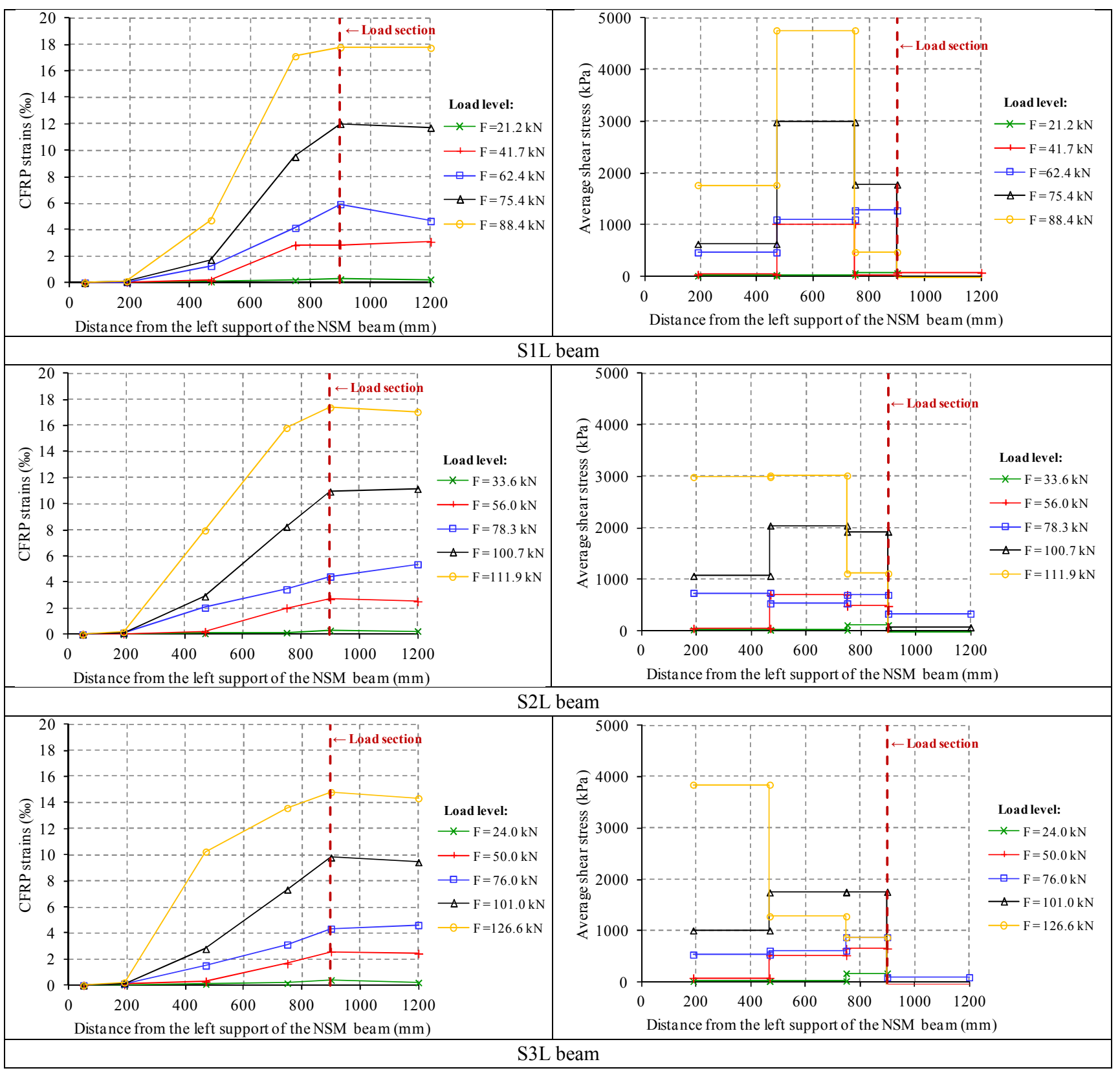

Fig. 10 - CFRP strain curves and average shear stress (see also Fig. 4). 


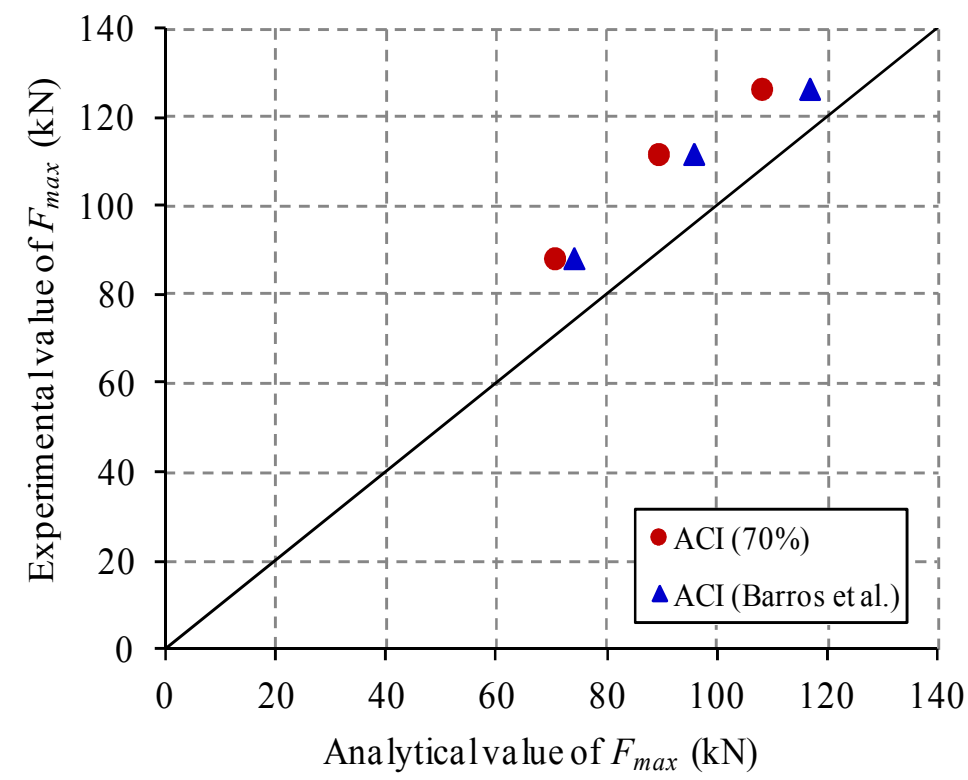

Fig. 11 - Comparison between the experimental and analytical values of the maximum load of the tested NSM beams.

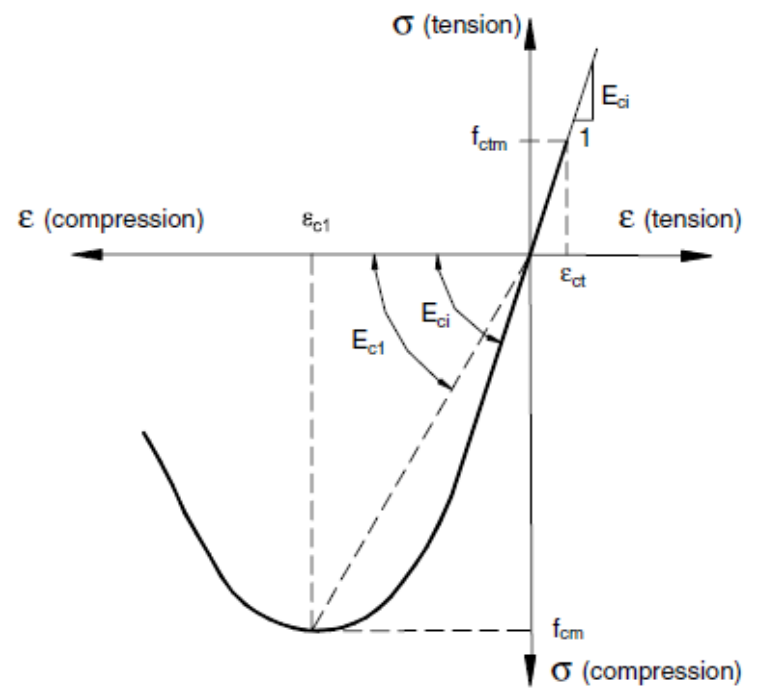

a)

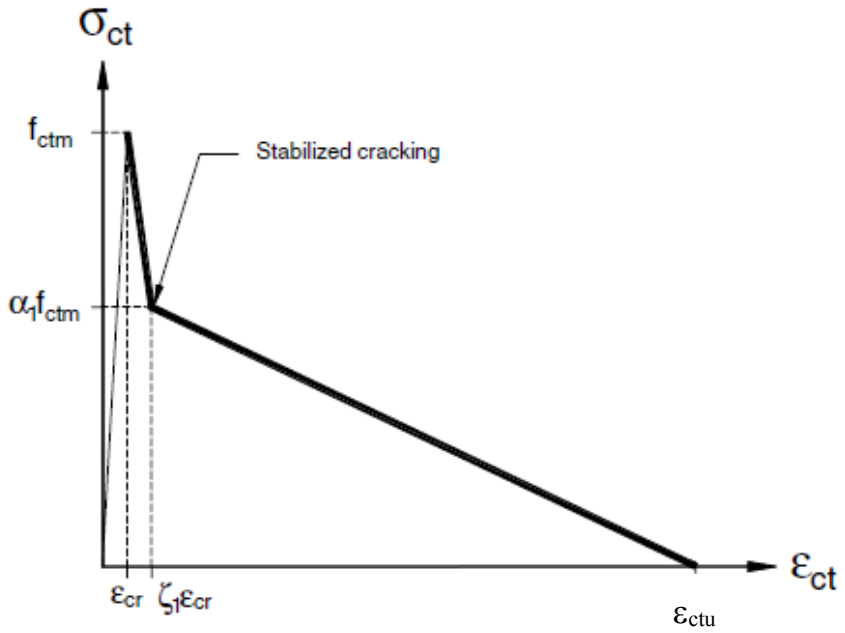

b)

Fig. 12 - Concrete laws used in the numerical simulation: a) in compression [23]; b) in tension [10]. 


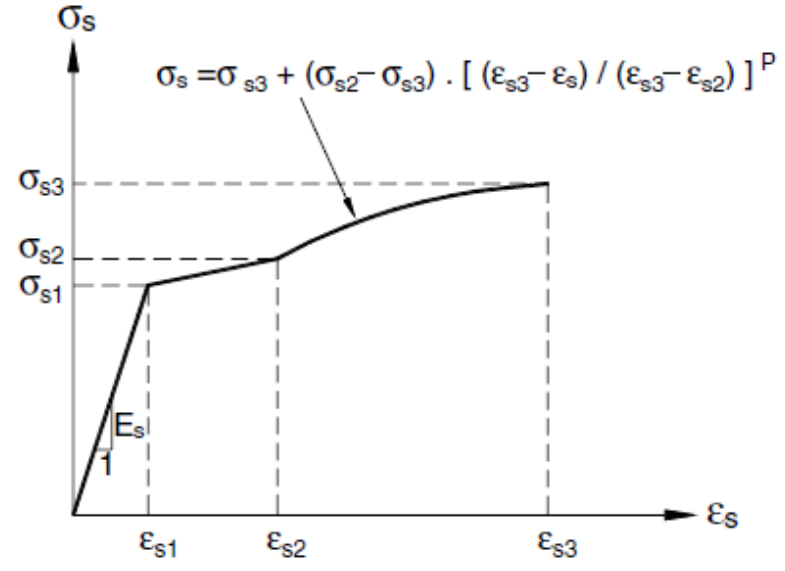

a)

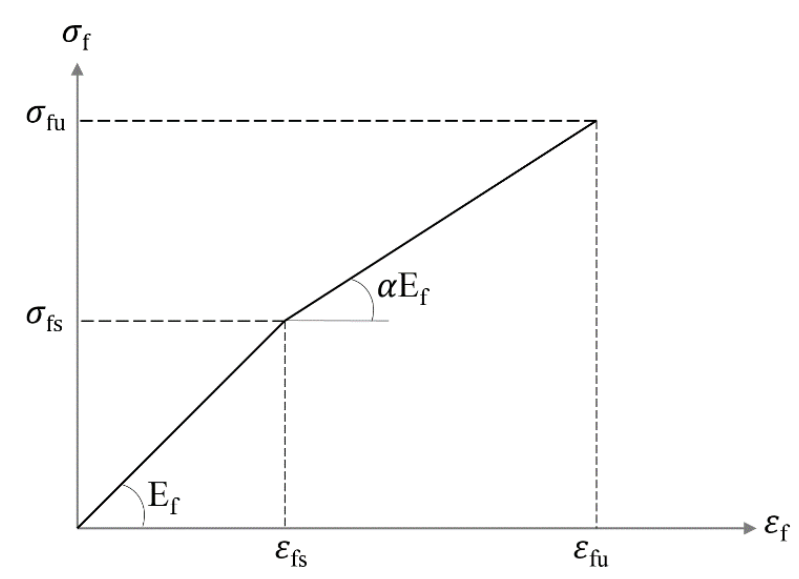

b)

Fig. 13 - Stress-strain relationship for the: a) steel bars [10]; b) CFRP laminates.

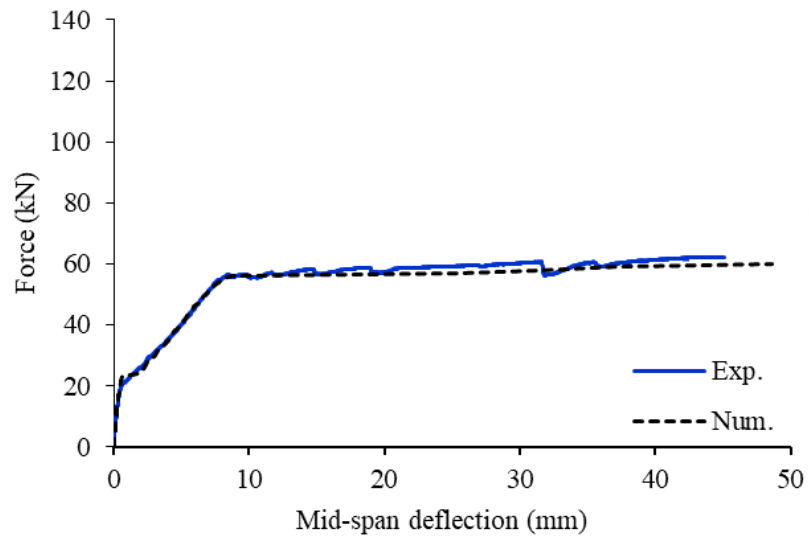

a)

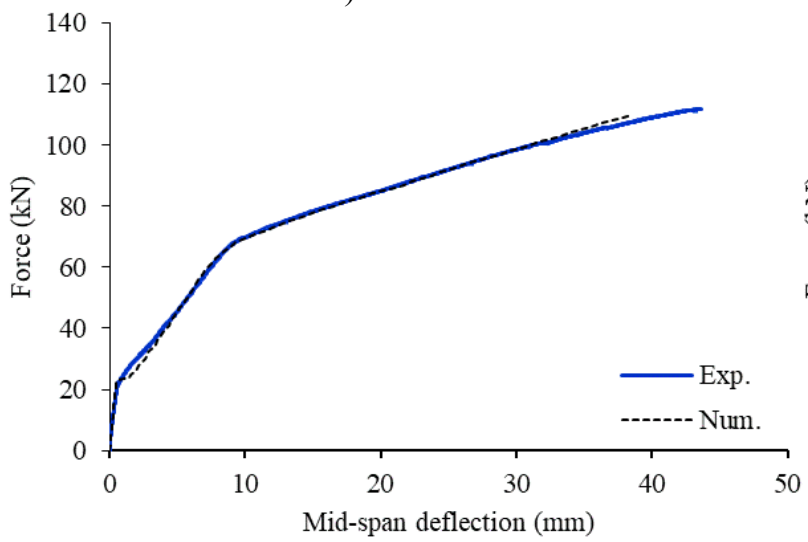

c)

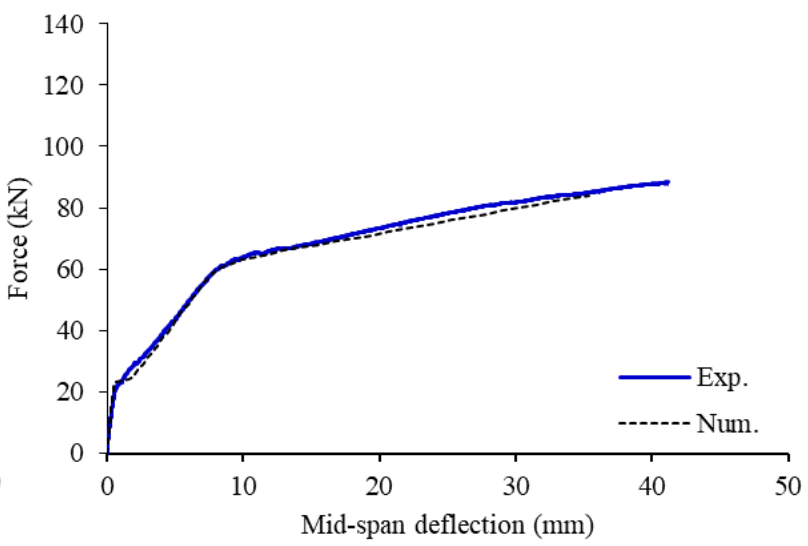

b)

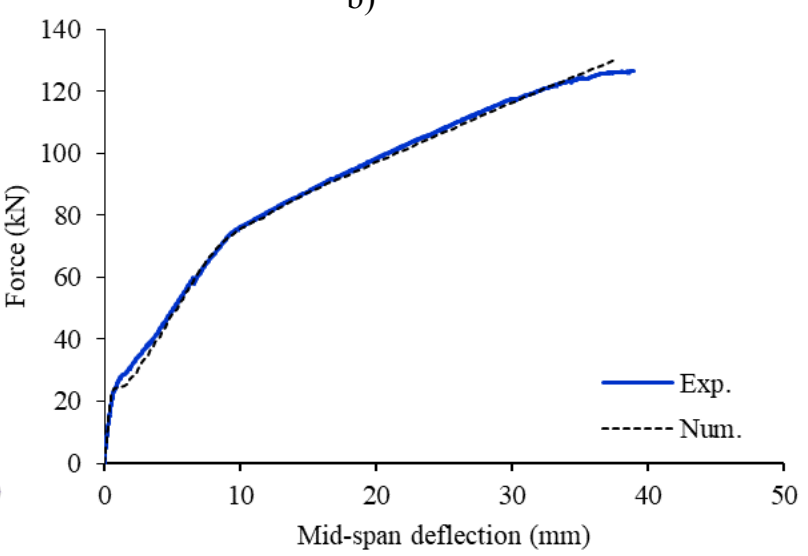

d)

Fig. 14 - Experimental vs. numerical force-deflection at mid-span for the tested RC beams: a) REF; b) S1L; c) S2L; d) S3L. 


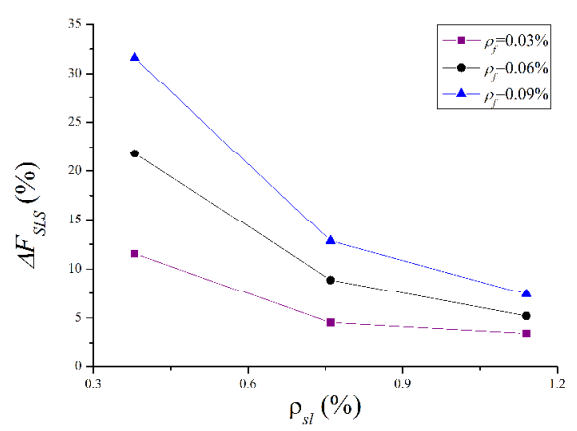

a) Concrete grade $C 25\left(f_{c k}=25 \mathrm{MPa}\right)$

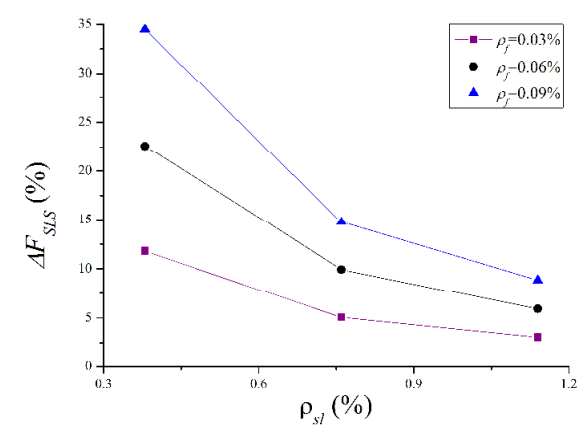

b) Concrete grade $\mathrm{C} 50\left(f_{c k}=50 \mathrm{MPa}\right)$

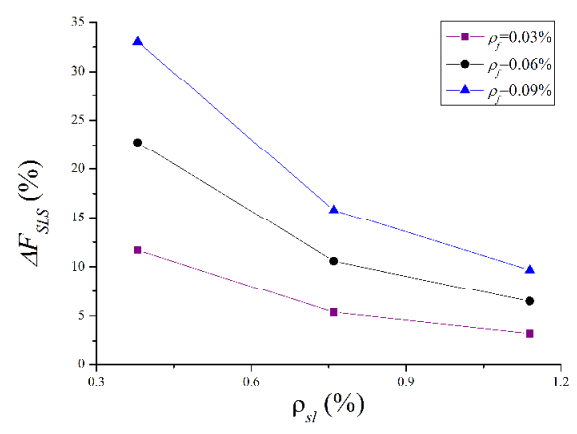

c) Concrete grade C70 $\left(f_{c k}=70 \mathrm{MPa}\right)$

Fig. 15 - Influence of the $\rho_{s l}$, $\rho_{f}$ and $f_{c k}$ on the NSM flexural strengthening performance in terms of load carrying capacity at serviceability limit state conditions, $\Delta F_{S L S}$.

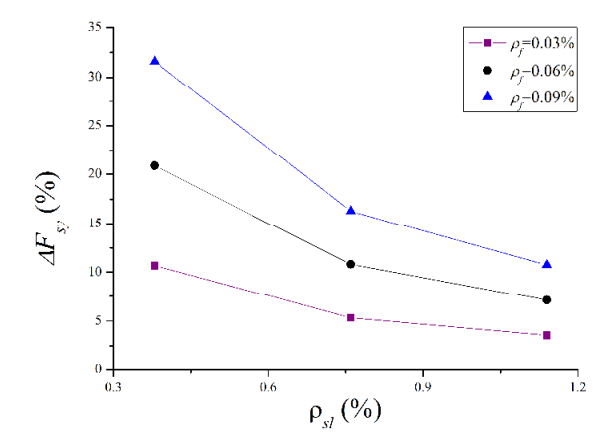

a) Concrete grade $C 25\left(f_{c k}=25 \mathrm{MPa}\right)$

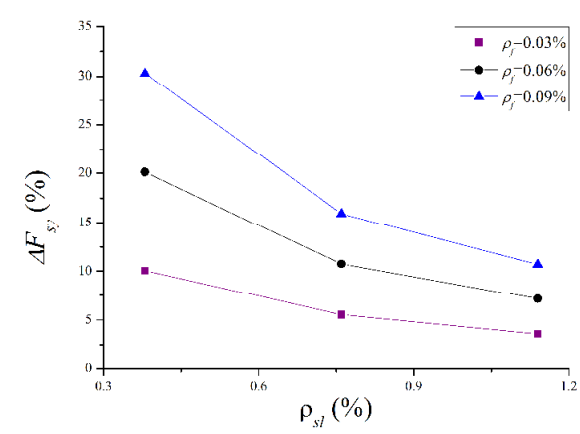

b) Concrete grade $C 50\left(f_{c k}=50 \mathrm{MPa}\right)$

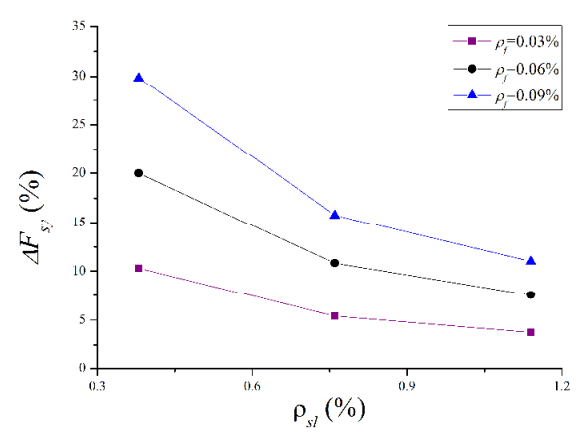

c) Concrete grade $C 70\left(f_{\text {ck }}=70 \mathrm{MPa}\right)$

Fig. 16 - Influence of the $\rho_{s l}, \rho_{f}$ and $f_{c k}$ on the NSM flexural strengthening performance in terms of load carrying capacity at yield initiation of the existing flexural steel reinforcement, $\Delta F_{s y}$.

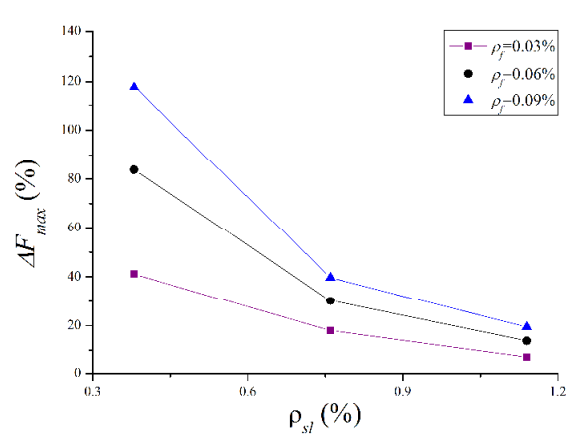

a) Concrete grade $C 25\left(f_{c k}=25 \mathrm{MPa}\right)$

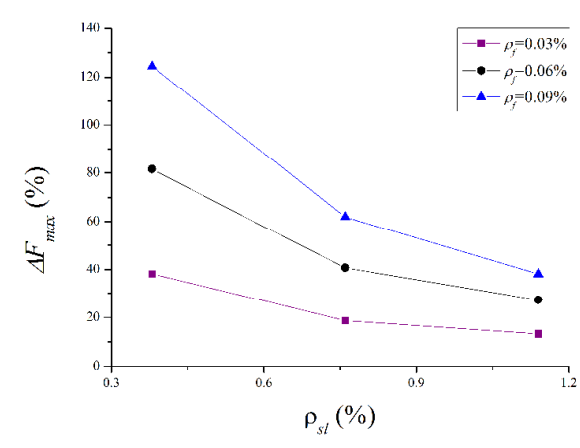

b) Concrete grade $C 50\left(f_{c k}=50 \mathrm{MPa}\right)$

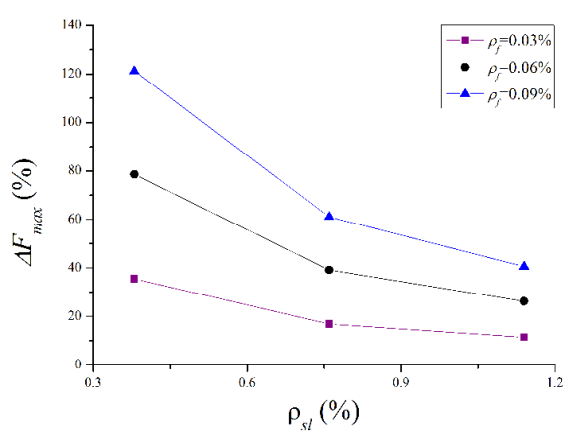

c) Concrete grade $C 70\left(f_{c k}=70 \mathrm{MPa}\right)$

Fig. 17 - Influence of the $\rho_{s l}, \rho f$ and $f_{c k}$ on the NSM flexural strengthening performance in terms of maximum load, $\Delta F_{\text {max }}$. 